\title{
ENSINO DE TRADUÇÃO: PERFIS E ABORDAGENS PEDAGÓGICAS DE DOCENTES BRASILEIROS E CANADENSES
}

\author{
Translation Teaching: Profiles And Pedagogical ApProaches \\ OF BRAZILIAN AND CANADIAN TEACHERS
}

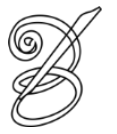 \\ Marileide Dias ESQUEDA* \\ Universidade Federal de Uberlândia, Brasil
}

\begin{abstract}
Resumo: Neste artigo, são apresentados os resultados da terceira etapa de uma pesquisa qualitativo-descritiva e de cunho exploratório sobre as abordagens pedagógicas adotadas por professores de prática de tradução em contexto canadense, em comparação com os dados coletados em contexto brasileiro. Em sua primeira etapa, iniciada em 2012, e utilizando questionários não estruturados, a pesquisa identificou o perfil acadêmico de 13 professores brasileiros de tradução e suas rotinas pedagógicas. Em 2017, como forma de dar continuidade à investigação, e levando em consideração que os professores modificam ou estabilizam suas práticas com o passar dos anos, a segunda etapa deste estudo adotou uma proposta de investigação qualitativo-longitudinal (FLORES, 2003), com o objetivo de identificar, junto ao mesmo grupo de professores brasileiros, as modificações que eles possam ter incorporado em suas salas de aula após cinco anos. Os participantes foram convidados a (re)avaliar os questionários respondidos em 2012 e a descrever as transformações sofridas em suas abordagens de ensino. Eles foram também convidados a analisar quais conteúdos consideram mais fáceis e mais difíceis de serem ensinados na sala de aula de prática de tradução (em geral). A terceira e última etapa deste estudo teve por objetivo identificar o perfil e descrever as abordagens pedagógicas adotadas por professores em contexto canadense e compará-las àquelas adotadas por professores brasileiros. Por meio dos resultados oriundos da aplicação de questionário, entrevista e de observações de aula, corroborou-se a hipótese de que a performance magistrale, que torna as soluções dos problemas tradutórios que surgem nos textos trabalhados em sala de aula dependentes da versão autorizada do professor, limitando a aprendizagem do aluno a uma instância de escutar e tomar notas, ainda prevalece em ambos os contextos.
\end{abstract}

Palavras-chave: Ensino de Tradução. Pedagogia da Tradução. Professor de Tradução. Análise comparativa Brasil-Canadá. Pesquisa Exploratória.

Abstract: This article aims at showing the results of the third phase of a qualitative-descriptive and exploratory research on pedagogical approaches adopted by translation practice teachers in Canada, in comparison to data collected in Brazil. Firstly, beginning in 2012, and using unstructured questionnaires, the proposal identified the academic profile of 13 Brazilian translation teachers and their pedagogical approaches. In 2017, as a way of continuing the research, and taking into account that teachers modify or stabilize their practices over the years, the second phase of the study adopted a qualitative-longitudinal research proposal (FLORES, 2003), with the objective of identifying, with the same group of Brazilian teachers, the modifications they may have incorporated in their classrooms after five years. Participants were invited to (re)evaluate the questionnaires answered in 2012 and to describe possible changes undergone in their teaching approaches. They were also invited to answer what content they find easy or difficult to teach in translation practice classes. The third and last phase of the investigation aimed at describing the pedagogical approaches adopted by translation teachers in Canada comparing them with those adopted by Brazilian teachers. Through the results from questionnaire application, interview and classroom observations, the hypothesis that the performance magistrale, which makes the solutions of translation problems that arise in texts worked in the class dependent on the authorized version of the teacher, and, at the same time, limiting the student's learning process to listening and taking notes, was confirmed for both contexts.

Keywords: Translation Teaching. Translation Pedagogy. Translator Trainer. Comparative Analysis BrazilCanada. Exploratory Research.

ESQUEDA, Marileide. Ensino de tradução: Perfis e abordagens pedagógicas de docentes brasileiros e canadenses. Belas Infiéis, Brasília, v. 9, n. 1, p. 127-166, 2020. 
RECEBIDO EM: 13 de maio de 2019

ACEITO EM: 18 de julho de 2019

PUBLICADO EM: janeiro 2020

\section{Introdução}

s últimas três décadas tornaram-se emblemáticas ao testemunhar o aumento dos
cursos universitários de formação de tradutores. Segundo os dados da European
Society for Translation Studies, há mais de 500 cursos de graduação e pós-graduação em Tradução ao redor do mundo e esse crescimento coincide com o aumento da investigação não apenas sobre a formação de futuros tradutores, mas também de professores e pesquisadores em Estudos da Tradução (VENUTI, 2017). E, se, por um lado, celebra-se a criação de novos cursos de formação de tradutores, por outro, busca-se melhor compreender as abordagens pedagógicas a serem adotadas no ensino e na aprendizagem da teoria e da prática de tradução. Nessa direção, as pesquisas conduzidas pelos autores aqui estudados suscitam discussões importantes, não apenas para a didática da tradução, isto é, para o que deveria ocorrer em sala de aula, mas também para sua pedagogia, entendida como um conjunto de princípios e métodos utilizados em sala de aula (FIOLA, 2003a).

Uma das formas de se ensejar a compreensão sobre a pedagogia da tradução é discutir as abordagens pedagógicas adotadas em sala de aula, que apesar de poderem contar com as contribuições advindas do socioconstrutivismo (VYGOTSKY, 1998), ainda estão ancoradas, em várias partes do mundo, na tradição transmissionista. Para Kelly (2005; 2010), a formação de tradutores centrada nessa tradição é antipedagagógica e frustrante para os alunos, já que as atividades de sala de aula se limitam a solicitar a tradução de textos jornalísticos, com pouca ou nenhuma preparação prévia dos alunos, para, em seguida, o professor oferecer sua própria versão "correta" como modelo, após a confirmação de que as versões dos alunos não têm qualidade profissional. Tal fórmula pedagógica foi inicialmente cunhada por Ladmiral (1979) como performance magistrale ${ }^{1}$.

Echeverri (2015) argumenta que:

No caso da performance magistrale, o trabalho dos alunos conta pouco porque, em última instância, o que eles deverão memorizar são as soluções de tradução propostas pelo professor. É nesse sentido que a ideia de igualar o desempenho profissional ao do professor não pode ser o objetivo final da formação. Visto desta maneira, a presença dos alunos nos cursos de formação de tradutores não determina nem a qualidade e nem a quantidade da aprendizagem. Diante dessa situação, a pergunta que surge naturalmente é: como explicar a perpetuação da prática da performance magistrale? (ECHEVERRI, 2015, p. 11, tradução nossa) ${ }^{2}$ 
Ao buscar explicar como o ensino transmissionista ainda faz parte da sala de aula de ensino de tradução, o autor afirma que cada geração de professores recebe as heranças de uma tradição e cultura que contribuem para a perpetuação de certas ações pedagógicas. Para Echeverri (2015), sem a formação pedagógica explícita, a partir da qual os professores poderiam ser expostos a progressos das Ciências da Educação e do ensino na área, o professor de Tradução recorre apenas à sua experiência pessoal, à sua própria história como tradutor ou como aluno de Tradução, repetindo as práticas dos professores que tiveram, deixando de guiarse por uma base de conhecimentos relativos aos avanços na formação de tradutores compartilhados pela comunidade científica.

Kiraly (2014) também faz críticas ao ensino transmissionista, centrado no professor, que utiliza a performance magistrale como fórmula pedagógica. $\mathrm{O}$ autor ressalta que essa abordagem convencional está fortemente estabelecida nas instituições dedicadas ao ensino da Tradução em muitos países, mesmo já se conhecendo seu efeito desmotivador, que geralmente advém do fato de atribuir aos estudantes um papel passivo, fazendo prevalecer a autoridade do professor. Para o autor:

[...] embora bastante utilizada ao longo dos anos, pouco tem sido escrito sobre a origem dessa técnica pedagógica específica e por que ela parece persistir como a base da formação de tradutores profissionais. Ninguém parece tê-la inventado especificamente para uso em aulas práticas de Tradução ou, pelo menos, não parece haver nenhum acadêmico da Didática da Tradução que orgulhosamente se responsabilize por tê-la criado. Portanto, podem haver evidências de que a abordagem "quem vai traduzir a primeira frase?" se baseie, de fato, em uma epistemologia popular e em uma práxis de segunda mão perpetuadas pela tradição - e na evidente falta de alternativas viáveis. (KIRALY, 2014, p. 2, tradução nossa) ${ }^{3}$

O ensino tradicional da Tradução, baseado na epistemologia do empirismoracionalismo, ainda é, para Kiraly (2014), demasiadamente dependente da intuição dos professores sobre o que os alunos devem saber e aprender. O problema da relativa ausência de programas acadêmicos direcionados à formação de professores de Tradução ${ }^{4}$ faz com que os docentes recorram às suas próprias intuições e à chamada abordagem do senso comum.

Colina (2015) argumenta que a aula tradicional de Tradução evidencia o que tem sido denominado como "complexo de Atlas" (em inglês Atlas Complex). O professor que sofre desse complexo carrega em seus ombros a inteira responsabilidade por tudo o que ocorre na sala de aula. Ele é o transmissor do conhecimento, e seus alunos são recipientes passivos cuja tarefa é imitar, o mais próximo possível, o conhecimento e a postura do professor. Para a autora, a sala de aula tradicional de Tradução exibe várias características indicativas da presença do 
“complexo de Atlas", tais como: a aula está centrada no professor; o professor é visto como um repositório do conhecimento e da verdade; as discussões feitas pelos alunos são mínimas, e quando ocorrem são sempre comandadas pelo professor. Ou seja, um aluno responde à questão posta pelo professor que por sua vez comenta a contribuição do aluno e depois volta-se para outro aluno; os alunos normalmente não interagem entre si; a interação é unilateral e geralmente limitada a diálogos nos quais o participante é sempre o mesmo - o professor; o papel dos alunos é passivo; espera-se que eles aprendam ao serem expostos ao conhecimento especializado que o professor possui.

Segundo Colina (2015):

\begin{abstract}
Além da prática pedagogicamente vulnerável de se esperar que os alunos sejam capazes de absorver o conhecimento do professor por estarem expostos a ele, a aula centrada no professor reafirma a visão de que a profissão de tradutor está em direta contradição com a experiência do mundo real. Em primeiro lugar, a sala de aula centrada no professor sugere haver "uma" tradução correta e que o professor a possui; em segundo lugar, implica haver "um" especialista com todas as respostas. Além disso, os papéis predominantes de professores e alunos na sala de aula tradicional inibem o desenvolvimento da autoconfiança dos alunos, negando-lhes os meios para defender e objetivamente argumentar a respeito de suas soluções específicas de tradução. O único critério de adequação é em que medida o produto da tradução imita a versão do professor. Uma vez que o modelo a ser imitado - o do professor especialista - não é apresentado (por exemplo, em um contexto profissional), o tradutor novato permanece sem critérios, frequentemente tentando obtê-los através da busca desesperada de outro modelo a seguir. (COLINA, 2015, p. 117)
\end{abstract}

Considerações semelhantes já haviam sido feitas, em cenário brasileiro, por Rosemary Arrojo (1993) acerca do papel do professor e do aluno de Tradução. Para a autora, outorgar ao professor o poder de "saber" traduzir e supostamente "possuir" as soluções corretas para os problemas de tradução se baseia na possibilidade de uma transferência impessoal de um conjunto de significados privilegiados de professor para aluno e de uma geração para outra. Segundo a autora, a pedagogia idealizada pela tradição locogocêntrica também se funda a partir do desejo (humanamente impossível) do apagamento da linguagem e de uma traduzibilidade exaustiva, associando o ensino à frustração e ao fracasso, cuja "meta única é a conquista do impossível" (ARROJO, 1993, p. 137), de uma onipotência que possa produzir uma tradução livre de qualquer "erro" e que sobreviva à passagem do tempo e às mudanças de contexto.

Também no Brasil, Darin (2001) realizou uma pesquisa com professores de cursos de graduação em Tradução, com o objetivo de estimular a revisão crítica da prática didática e das estratégias de ensino adotadas nos cursos voltados para a formação de tradutores, sendo este um dos trabalhos pioneiros no país a explorar o fazer diário do professor de tradução, pelo 
menos até onde se tem conhecimento. As respostas dos docentes de quatro universidades brasileiras, segundo a autora, revelaram, à época, falta de consenso entre os educadores sobre os parâmetros utilizados, por exemplo, para a seleção dos textos, sendo os critérios pedagógicos declaradamente subjetivos e aparentemente arbitrários. Os professores investigados no estudo de Darin (2001) centralizam e controlam o processo de aprendizagem, responsabilizando-se pela avaliação das traduções e oferecendo as soluções diante de impasses.

É, portanto, neste universo de discussões que esta pesquisa se insere. Vislumbrando dar continuidade ao estudo de Darin (2001) e às discussões implementadas na literatura concernente à Pedagogia da Tradução, foi desenvolvida a pesquisa Ensino de Tradução: Culturas Pedagógicas ${ }^{5}$, buscando corroborar a hipótese de que as proposições teóricas, principalmente aquelas que se mostram contra a performance magistrale implementada desde há muito no ensino da Tradução (ARROJO (1993); DARIN (2001); COLINA (2015); KELLY (2005); KIRALY (1995; 2000; 2014), ECHEVERRI (2015; 2018) não têm sido suficientes a ponto de fazerem com que haja uma nova concepção sobre a Pedagogia da Tradução.

A pesquisa foi dividida em três grandes etapas. De viés qualitativo-descritivo e exploratório, a primeira etapa do estudo, realizada no ano de 2012, buscou, por meio de questionários não estruturados, conhecer e descrever o perfil dos professores de tradução que atuam em cenário brasileiro, bem como as abordagens pedagógicas adotados por eles em sala de aula de prática da tradução ${ }^{6}$. A segunda etapa, implementada em 2017, e portanto de caráter qualitativo-longitudinal (FLORES, 2003), identificou, junto aos mesmos professores entrevistados na primeira etapa, como eles (re)descrevem seu perfil e (re)definem seus saberes docentes após cinco anos, já que a natureza dos saberes docentes é dinâmica, processual e complexa, podendo sofrer mudanças conforme passam-se os anos de experiência docente (TARDIF, 2002; PIMENTA, 2016; CHARLOT, 2000, 2001, 2005). Os resultados advindos de ambas as etapas da pesquisa podem ser encontrados na íntegra em Esqueda (2018), mas serão brevemente expostos na próxima seção, para fins de comparação com os dados da terceira etapa da pesquisa. A terceira e última etapa da pesquisa teve como proposta identificar, por meio de questionários não estruturados, entrevistas e observações de aula, as abordagens pedagógicas adotadas por professores de uma universidade canadense ${ }^{7}$ que oferta curso de graduação em Tradução, com vistas a comparar seus resultados com os dados das primeira e segunda etapas.

Espera-se, com os resultados apresentados neste artigo, contribuir para a melhor compreensão da Pedagogia da Tradução e dos diversos aspectos que envolvem a Tradução em 
contexto de ensino e aprendizagem. Para Echeverri (2018, p. 39, tradução nossa) ${ }^{8}$, "o desafio imediato da Pedagogia da Tradução é superar essa última fronteira, que é a sala de aula”.

\section{1 que já se sabe acerca da pedagogia adotada por professores de prática da tradução no Brasil?}

Para fins de concisão, esta seção apresentará, brevemente, os resultados das primeira e segunda etapas da pesquisa Ensino de Tradução: Culturas Pedagógicas, que teve início em 2012. (cf. ESQUEDA, 2018)

Foi implementada uma investigação qualitativo-descritiva e de cunho exploratório que, por meio de questionários não estruturados, buscou conhecer e descrever o perfil dos professores de Tradução que atuam em diferentes instituições brasileiras que ofertam cursos de graduação em Tradução, bem como identificar como esses docentes definem seus saberes e descrevem suas abordagens pedagógicas em sala de aula. Assim, foram traçados os seguintes objetivos específicos: 1) identificar o perfil dos docentes de diferentes instituições públicas e privadas de ensino superior que ofertam o curso de graduação em Tradução, principalmente no

132 que tange à sua formação acadêmica, área de atuação, pesquisa e aperfeiçoamento; 2) levantar e discutir como os professores definem seu modelo de saberes e como esse se reverte em ações no fazer diário da sala de aula de prática da tradução; 3) analisar quais fatores se mostram determinantes para o desdobramento dos saberes e perfis dos professores de tradução em contexto brasileiro.

Foram incluídos, nessa etapa, os professores universitários brasileiros que ministram aulas práticas em cursos de graduação em Tradução em universidades públicas e privadas, identificados através do site www.emec.gov.br. A identificação das instituições no site resultou em 12 instituições brasileiras que ofertavam cursos de Tradução, tendo sido convidados os professores de Tradução de cada uma dessas instituições, totalizando um universo de seis professores de instituições públicas e sete de instituições privadas que aceitaram participar do estudo.

Após serem informados a respeito dos objetivos da pesquisa, cada professor entrevistado respondeu dois questionários não estruturados, respectivamente Q1 - Questionário 1-Perfil dos docentes; Q2 - Questionários 2-Questões relativas à prática docente. A aplicação do Q1 visou colher informações pessoais, formação acadêmica e experiência profissional dos docentes. O Q2 teve como objetivo verificar as principais abordagens pedagógicas que eles utilizam em sala de aula para apresentação e avaliação dos conteúdos ministrados, quais fatores 
influenciam sua prática docente, o que é ser um bom professor de Tradução, e, por último, como o professor delineia seus saberes docentes.

\subsection{Resultados da primeira etapa}

Dos 13 entrevistados, com idade média entre 34 e 61 anos, sete possuem graduação em Letras e seis em Tradução. Com relação à formação em nível de mestrado, seis possuem mestrado em Estudos da Tradução, dois em Teoria Literária, dois em Linguística Aplicada ao Ensino de Línguas, um em Análise do Discurso, um em Semiótica e outro em Linguística. Com relação à formação em nível de doutorado, quatro dos entrevistados não possuem o título (segundo os dados obtidos em 2012), seis possuem doutorado em Estudos da Tradução, um em Teoria Literária, um em Semiótica e um em Fonoaudiologia. Dois docentes afirmam ter pósdoutorado em Tradução em universidades estrangeiras.

A média de experiência com o ensino de Tradução é de 14 anos dos docentes das instituições particulares, sendo que P6 possui 30 anos de experiência no ensino de Tradução, e de aproximadamente quatro anos dos docentes pertencentes às instituições públicas.

$100 \%$ dos docentes das instituições particulares (sete docentes) afirmaram ter experiência profissional como tradutores ou intérpretes. Um deles é tradutor público e intérprete comercial. No caso dos seis docentes das instituições públicas, dois afirmaram nunca terem traduzido. Os outros quatro prestam serviços de tradução a clientes do próprio ambiente acadêmico em que atuam e a editoras. Um deles é tradutor público e intérprete comercial. Ainda em relação ao Q1, 84\% dos entrevistados não fazem parte de associações ou de outras instituições ligadas à classe de tradutores.

Pode-se depreender dos dados coletados no Q1 que os 13 professores entrevistados têm perfil diversificado em relação à área de formação, idade e ao tempo de docência no ensino de Tradução, o que poderá, a partir dos dados do Q2, evidenciar a ausência de uma prática docente padronizada para o ensino de Tradução e a não incorporação dos avanços teóricos e científicos à sala de aula, resultados estes que também emergirão dos dados coletados, em 2019, junto a professores do contexto canadense.

Com relação ao Q2, as descrições gerais feitas pelos professores quanto à abordagem pedagógica que implementam em seus contextos, tem-se que:

- as aulas são expositivas e realizadas em laboratório de informática;

- o professor contextualiza o assunto; 
- os gêneros textuais são apresentados pelo professor antes da realização das traduções;

- há exposição e discussão sobre o conteúdo do texto que será traduzido;

- após as orientações, a tradução é encomendada como atividade extraclasse, sendo que o aluno deve finalizá-la fora do contexto da sala de aula;

- em aula posterior, os alunos leem excertos do texto traduzido para o professor e colegas; alguns alunos são sorteados para a apresentação oral de suas traduções;

- o professor discute as opções dos alunos, avaliando a consistência terminológica do texto;

- há utilização de referenciais teóricos com o intuito de diminuir o percentual de dúvidas sobre o que é uma tradução fiel.

Ainda com relação às abordagens pedagógicas, P9 e P13, ambos docentes de instituições públicas, mencionaram haver a utilização de sistemas de memória de tradução na rotina de elaboração das traduções em sala de aula. P9 também afirmou não haver dedicação ao processo de revisão durante as aulas. P6 afirmou escolher os textos a serem traduzidos por temas ou por números de palavras (de 280 a 350 palavras em disciplinas introdutórias; e de 350 a 500 palavras em disciplinas avançadas). P11, que ministra todas as disciplinas de prática de tradução na instituição à qual pertence, quais sejam, prática da tradução de textos acadêmicos, comerciais, jurídicos e literários, afirmou solicitar, em média, dez páginas a serem traduzidas, sendo que os alunos traduzem metade em sala e metade como atividade extraclasse.

As abordagens pedagógicas relatadas pelos entrevistados atestam a inexistência de consenso entre os professores com relação aos critérios norteadores da formação de tradutores, ou seja, utilizam critérios subjetivos e aparentemente arbitrários para a seleção dos textos a serem traduzidos pelos alunos e utilizam predominantemente a fórmula pedagógica da performance magistrale, a partir da qual o professor busca avaliar a consistência e o conteúdo correto dos textos traduzidos.

Os docentes entrevistados mostram, de maneira geral, que adotam atividades convencionais, nas quais se realizam a leitura do texto original, a sua tradução preliminar de forma oral, a elaboração da tradução pelos alunos em intervalo de tempo pré-estipulado, durante o qual os alunos devem aprender a traduzir traduzindo e, por último, a posterior verificação das opções de tradução junto a todos os alunos. Outros professores agregam a essa prática outras atividades que, no entanto, são implementadas à rotina pedagógica de maneira isolada e assistemática. 
Com relação aos critérios de avaliação das traduções realizadas, os docentes do contexto brasileiro apontaram a utilização de pseudônimos para que as traduções sejam avaliadas às cegas; paratextos para o registro de justificativas quanto às escolhas tradutórias feitas pelos alunos; feedback individual; chamada oral; tradução autocomentada para que o aluno tome ciência de suas escolhas; provas teóricas e práticas, com elaboração de glossários; e atribuição de metade dos pontos por traduções feitas em sala e outra metade pelas traduções feitas fora da sala de aula.

Embora já se encontrem vestígios de uma avaliação formativa de tradução nesses relatos (COLINA, 2015; KELLY, 2005), em que as justificativas dadas pelos alunos com relação à adoção de estratégias de tradução são incorporadas ao sistema de avaliação, os professores entrevistados, em geral, centralizam e controlam o processo de aprendizagem, responsabilizando-se pela avaliação das traduções e oferecendo soluções diante de impasses.

Quanto aos fatores que mais influenciam/influenciaram as práticas adotadas pelos docentes em sala, dos 13 docentes entrevistados, oito responderam que o que mais influenciou e influencia suas atuações como professores de Tradução é o fato de serem tradutores. Entre a maioria dos docentes, prevalece, portanto, a concepção de que ser tradutor profissional é o que confere ao docente uma atuação mais sólida e, por consequência, autoridade para avaliar seus alunos. Outros fatores relacionados aos saberes docentes não foram relatados.

Com relação à forma como os docentes de Tradução definem seus saberes, os participantes afirmaram, majoritariamente, que todo professor de Tradução deve ser tradutor, o que pressupõe o conhecimento linguístico e o conhecimento acerca dos diversos gêneros textuais e suas características, segundo os próprios entrevistados. Os participantes também afirmaram que o professor deve dominar ferramentas e ter experiência de mercado e que, além disso, deve saber ouvir; saber explicar e transmitir sua experiência aos alunos; saber aceitar as diferenças; ter carisma; ter boa convivência com os alunos; gostar de lecionar; ser sincero com a relação à remuneração que o mercado oferece; curioso; inquieto; interessado; atento; deve perceber as limitações dos alunos e saber saná-las na hora certa.

Quando indagados sobre o que é ser um bom professor de Tradução, os participantes apontaram que é aquele que se mantém atualizado com relação às práticas do mercado; esclarece os malefícios das crenças sobre Tradução; corrige os erros, mas também aponta os aspectos positivos das traduções dos alunos; aceita as diversas opções de tradução trazidas pelos alunos; tem autoridade para corrigir os alunos por ser um tradutor reconhecido; para P6, o professor que é tradutor premiado (no setor editorial) sabe dominar a sala de aula. 
Apesar do reduzido universo de participantes que aceitaram participar da pesquisa, as informações coletadas nos Q1 e Q2 podem servir como um primeiro retrato sobre como os professores brasileiros descrevem suas abordagens pedagógicas e como definem seus saberes docentes.

Observa-se, em linhas gerais, a ausência de diretrizes pedagógico-metodológicas comuns na sala de aula de Tradução, não havendo consenso sobre o modo como os textos poderiam ser abordados e traduzidos em sala. No que concerne aos saberes do docente de Tradução, observa-se que os participantes privilegiam a competência profissional e mercadológica do professor, que estaria atrelada a apenas um dos saberes docentes retratados por Pimenta (2016), isto é, os saberes da formação profissional. Os entrevistados não revelaram em seus comentários outros saberes docentes tais como o pedagógico, curricular e experiencial, tampouco citaram a articulação entre eles, revelando uma atuação ainda pouco preocupada com a didática e a pedagogia e mais interessada no saber prático (formação profissional).

Por ainda inexistirem pesquisas sobre os saberes do professor de Tradução, entendidos aqui como um construto que engloba a capacidade de gerenciamento e adoção de metodologias

136 de ensino, embasamento teórico e prático concernente à disciplina que se ensina, uma disposição para se realizarem ações com propósitos pedagógicos relacionados a outras disciplinas do currículo, aos avanços da área e à capacidade de reflexão diária acerca da experiência profissional acumulada (PIMENTA, 2016), é que se inseriram as propostas de continuação desta investigação. Na seção seguinte, serão brevemente relatados os dados da segunda etapa da investigação, coletados em 2017, envolvendo os mesmos docentes entrevistados em 2012, e, nas seções 2 e 3, a continuação da investigação, em 2019, no contexto de uma universidade canadense que oferta curso de graduação em Tradução.

\subsection{Resultados da segunda etapa}

Embora os achados da primeira etapa tenham evidenciado perfis heterogêneos de docentes que concebem o saber profissional e mercadológico como o mais importante para o âmbito da sala de aula, na qual perpetua o ensino centrado no professor, ressalta-se que a natureza dos saberes docentes é dinâmica, processual e complexa, podendo sofrer mudanças conforme passam-se os anos de experiência docente.

Assim, a segunda etapa desta pesquisa buscou investigar como os mesmos docentes reconstroem o seu próprio itinerário formativo ao longo de suas carreiras e os modos como 
valorizam as pesquisas sobre o ensino na área, os diferentes contextos e processos de formação e de desenvolvimento profissional.

Tratou-se de dar continuidade à pesquisa qualitativo-descritiva de cunho exploratório e, nesta etapa, longitudinal (FLORES, 2003), com amostragem dispersa (podendo ou não contar com o mesmo número de participantes da etapa anterior), que, por meio de instrumentos não estruturados (entrevistas abertas realizadas pessoalmente, via software online de comunicação em audio e vídeo e por correio eletrônico), buscou identificar como os professores de Tradução (re)descrevem seu perfil e (re)definem seus saberes docentes após cinco anos da realização da pesquisa anteriormente respondida.

Para além do caráter retrospectivo, esta nova etapa da pesquisa incluiu o seguinte conjunto de perguntas: A formação contínua do professor de Tradução é importante? Quais seriam os temas de seu maior interesse e em qual ordem de importância? Quais modalidades de ações formativas mais corresponderiam às suas necessidades cotidianas de sala de aula? Em sua opinião, quais conteúdos são mais difíceis e mais fáceis de serem trabalhados em sala de aula?

Após cinco anos, foi possível estabelecer contato e obter respostas de 10 dos 13 docentes que participaram da pesquisa em 2012, sendo cinco das instituições particulares e cinco das instituições públicas investigadas.

Com relação às mudanças realizadas nos questionários respondidos em 2012, um dos dez participantes não alterou quaisquer informações nos Q1 e Q2, nem sequer a idade ou tempo de experiência, atestando que adota as mesmas abordagens pedagógicas já explicitadas e demonstrando pouco interesse em participar da nova etapa de pesquisa, sendo que outro apenas alterou a idade e o tempo de experiência na docência.

Quando indagados sobre suas atividades como profissionais da Tradução, os oito participantes que decidiram modificar o questionário relataram traduzir em paralelo às atividades de docência, atendendo principalmente ao âmbito acadêmico ao qual pertencem. Em comparação com os dados coletados em 2012, houve uma modificação no perfil dos docentes de instituições públicas, que passaram a traduzir mais. Os dados indicam que o fato de serem tradutores reconhecidos e poderem ter mais autoridade para corrigir seus alunos se fortaleceu.

Ao reavaliarem se as escolhas das abordagens pedagógicas adotadas em sala sofreram alguma alteração, a maioria dos participantes não relatou quaisquer alterações nas abordagens pedagógicas adotadas. Um participante, no entanto, acrescentou solicitar aos alunos que complementem as traduções com reflexões sobre as estratégias e soluções utilizadas. Dois 
participantes afirmaram ter transformado as disciplinas práticas em projetos de tradução mais duradouros, sendo que aos textos a serem traduzidos foram acrescentadas outras atividades preparatórias envolvendo público-alvo, função comunicativa do texto e outras informações relativas ao tipo e gênero textuais.

Os docentes também não modificaram o rol de saberes que delinearam para o professor de Tradução na pesquisa de 2012. Reiterou-se o fato de que o professor tem que ter experiência como tradutor. No entanto, um docente acrescentou que o professor de Tradução deve preocupar-se em avaliar o aluno de forma menos subjetiva.

Os dados retrospectivos que emergem dessa coleta são importantes por considerarem a natureza dinâmica, processual e complexa da docência, sobretudo a partir da própria percepção e relato dos docentes no decorrer, neste caso, de cinco anos. Embora sem contar com uma investigação exaustiva das biografias pessoais dos docentes investigados, pode-se inferir que o aprimoramento da carreira do professor de Tradução têm ocorrido de forma autônoma e assistemática, na própria sala de aula, sendo que as teorias e investigações relativas ao ensino de Tradução pouco têm impactado na atuação do professor de Tradução em cenário brasileiro.

138 E, muito embora dois dos oito docentes que mencionaram ter transformado as disciplinas práticas em projetos de Tradução mais duradouros, essa "nova" pedagogia relatada, apesar de válida e bem-vinda, ainda tem formato subjetivo e assistemático, equiparando-se aos achados de Darin (2001).

Com relação à primeira pergunta dos dados prospectivos, verifica-se que $100 \%$ dos participantes manifestaram interesse pela formação contínua, considerando-a essencial, o que revela o compromisso dos docentes com o seu processo de desenvolvimento profissional.

Quanto aos assuntos de interesse para fins de formação contínua, os professores mencionaram que gostariam de aprimorar seus conhecimentos no tocante às novas tecnologias, principalmente com relação às ferramentas de auxílio à tradução, como os sistemas de memória de tradução, tradução automática e pós-edição. Três participantes destacaram, além disso, a necessidade de aprimoramento na prática da tradução audiovisual. Quanto ao interesse em aprimorar-se didaticamente, quatro docentes referiram-se à necessidade de cursos de formação contínua que tratem especificamente da elaboração de materiais.

Quando indagados quais disciplinas são mais fáceis e difíceis de serem trabalhadas em sala, 50\% dos participantes da pesquisa consideram as disciplinas de prática de tradução mais difíceis de serem ensinadas, podendo-se inferir que a formação que o professor recebe nos programas de mestrado e doutorado em Estudos da Tradução parece suprir formas de ensino da 
teoria, em detrimento de sua articulação com a prática. Com relação ao restante dos participantes, 30\% mencionaram que ambas as disciplinas são difíceis de serem ensinadas e outros $20 \%$ mencionaram que depende da experiência do professor.

Para resumir, a pesquisa, em suas duas primeiras etapas, teve como proposta, implementada inicialmente em 2012, identificar o perfil de docentes de Tradução em cenário brasileiro e suas percepções sobre seus próprios saberes docentes; e como proposta posterior, que ocorreu após um intervalo de cinco anos, em 2017, examinar se a performance magistrale persiste ou se ocorreram mudanças nas abordagens pedagógicas em sala de aula e o que se mostra mais difícil e mais fácil de ser trabalhado com os alunos.

O que emerge dos dados, como já mencionado, é que o aprimoramento da carreira do professor de Tradução têm ocorrido de forma autônoma, na própria sala de aula, corroborando a hipótese de que a performance magistrale é perpetuada, principalmente quando o professor baseia-se em suas próprias referências dos professores (e colegas) que o antecederam e em suas experiências como tradutor.

A partir desses achados, descreve-se, a seguir, a terceira e última etapa da pesquisa Ensino de Tradução: Culturas Pedagógicas, que vislumbrou identificar o perfil de professores de Tradução de uma instituição canadense, quais as abordagens pedagógicas por eles adotadas e como definem seus saberes. Nesta etapa, além da coleta de dados envolvendo questionários e entrevistas, foram realizadas observações de aulas, com o intuito de relacionar as respostas dos participantes a suas decisões em sala de aula.

\section{Pressupostos metodológicos da terceira etapa}

Para Cohen et al. (2018), embora se critique o fato de que a delimitação de hipóteses não deveria fazer parte do paradigma de pesquisas de cunho qualitativo na era pós-positivista, nenhum estudo científico é livre de antecedentes e parte, inevitavelmente, de dados prévios, ao mesmo tempo preparando-se para descobrir algo novo.

Assim, ainda centrada no tipo de pesquisa qualitativo-descritiva de cunho exploratório, partiu-se da mesma hipótese norteadora das etapas da pesquisa qualitativo-descritiva de cunho exploratório e longitudinal anteriormente descritas, ou seja, de que as propostas teóricas sobre ensino de Tradução e seus avanços, que se mostraram contra o ensino centrado no professor, não têm surtido o efeito esperado a ponto de fazerem com que haja uma nova concepção sobre a Pedagogia da Tradução. 
O objetivo principal desta etapa, ao identificar dados concernentes ao perfil de professores de Tradução em contexto canadense, como estes definem seus saberes docentes e se utilizam a performance magistrale como fórmula pedagógica (cf.: nota de rodapé número 7), foi compará-los à realidade brasileira. Assim, foram delineados os seguintes objetivos específicos: 1) identificar o perfil de docentes de uma universidade canadense da cidade de Montréal, no Canadá, que oferta o curso de graduação em Tradução, principalmente no que tange à sua formação acadêmica, área de atuação, pesquisa e aperfeiçoamento; 2) identificar como os professores definem seu modelo de saberes e como esse se reverte em ações no fazer diário da sala de aula de prática da tradução; 3) comparar os dados coletados à realidade brasileira de ensino de Tradução descritos anteriormente e publicados na íntegra em Esqueda (2018).

Os instrumentos de pesquisa utilizados nesta etapa encontram semelhança aos das etapas anteriores, porém foram adequados ao contexto de investigação. Assim, o Q1 aplicado em contexto brasileiro foi traduzido para o inglês, visando colher informações pessoais, formação acadêmica e experiência acadêmica e profissional dos docentes. Para que se pudesse averiguar 140 algumas especificidades do contexto canadense, o Q2 aplicado junto aos professores brasileiros foi transformado em entrevista não estruturada, aplicada em língua inglesa junto aos participantes canadenses, sendo que as perguntas prospectivas da pesquisa longitudinal da segunda etapa foram aglutinadas à entrevista. Além disso, esta terceira etapa da pesquisa contou com um período de um mês de observações de aulas ${ }^{9}$ dos participantes envolvidos no estudo, com o intuito de relacionar suas respostas às decisões por eles tomadas em sala de aula.

O Q2, transformado em entrevista estruturada, sofreu alteração na ordem das perguntas. Embora todas as 11 questões da entrevista do tipo estruturado e de questões abertas (standardized open-ended interview) pudessem nos levar direta ou indiretamente à confirmação da hipótese norteadora da pesquisa, de que as propostas teóricas que se mostram contra o ensino centrado no professor ainda não surtiram efeito na sala de aula de ensino de Tradução, a mais importante delas, "Como você descreveria suas típicas aulas de prática de tradução?” (How would you describe your typical translation practice courses?), isto é, aquela que poderia expressar o mais alto nível de autenticidade, riqueza e profundidade de resposta para fins de comparação com o contexto brasileiro, foi colocada em sétimo lugar no roteiro das questões da entrevista. Para Cohen et al. (2018), é importante elaborar questionários ou entrevistas colocando em primeiro lugar perguntas mais gerais ou de simples resposta, e alocando aquelas mais longas e complexas, e de grande interesse dos pesquisadores, para a metade do tempo 
destinado à entrevista, momento em que, além de mais familiarizados com o pesquisador e com as perguntas do instrumento, os participantes possam se sentir mais estimulados em respondêla. (cf. COHEN et al., 2018, capítulos 24 e 25).

Embora a entrevista estruturada de questões abertas siga, como o nome deixa antever, uma estrutura, e muito embora a pesquisadora tivesse tentado se ater à ordem das perguntas, houve momentos em que os participantes desviaram-se do objetivo principal das perguntas, sendo que a pesquisadora, em momento oportuno, buscou retomá-lo. Para Walford (2001, p. 90), esse instrumento de pesquisa é, por natureza, caracterizado como um encontro entre pesquisador e participante, em que, "entrevistadores e entrevistados coconstroem a entrevista" $^{10}$. Sendo a entrevista um encontro social e não apenas uma simples troca de informações, buscou-se reservar entre 60 a 90 minutos para sua realização, já contando com a troca de ideias e o desvio dos objetivos principais das perguntas. As respostas não foram gravadas, mas transcritas pela pesquisadora no processador de textos do programa computacional Word, da empresa Microsoft. As respostas, à medida que foram sendo transcritas literalmente, eram lidas ao participante, que poderia se certificar de que estavam condizentes com suas concepções e com o que haviam de fato dito.

Adotou-se, além do questionário e da entrevista, um protocolo estruturado de observação de aulas. Esse instrumento, elaborado com base em Cohen et al. (2018), foi acrescentado à pesquisa por dois motivos principais: para evitar preconcepções da pesquisadora, guiadas pelos dados dos resultados das etapas anteriores da pesquisa, e para averiguar se as formas como os professores descrevem suas abordagens pedagógicas se assemelham àquelas por eles efetivamente adotadas em sala.

Com vistas a buscar o controle menos subjetivo possível das categorias de observações, optou-se pela observação estruturada, permitindo assim gerar dados numéricos e facilitando a frequência de padrões a serem anotados. Para Cohen et al. (2018, p. 546), a elaboração do protocolo de observação do tipo altamente estruturado leva tempo para ser elaborado, porém sua coleta e análise são relativamente rápidas, uma vez que bastará ao pesquisador apenas marcar com um "x", por exemplo, o que o professor está fazendo em sala e por quanto tempo. No caso do instrumento elaborado para essa etapa da pesquisa, optou-se por marcar com um "x", a cada 15 minutos (COHEN et al., 2018), as ações tomadas pelo professor em sala de aula, como, por exemplo, a ação de corrigir as sentenças traduzidas oralmente pelos alunos utilizando a lousa ou um datashow, tomando como base suas próprias opiniões enquanto professor e tradutor profissional, como exemplificado no Quadro 1. 
Quadro 1 - Exemplo de uma categoria a ser selecionada no protocolo de observação de aula

\begin{tabular}{|c|c|c|c|c|c|c|c|c|c|c|c|c|c|}
\hline \multirow[t]{2}{*}{ Categoria } & \multicolumn{12}{|c|}{ Duração (categoria selecionada a cada 15 minutos) } & \multirow{2}{*}{$\begin{array}{c}\text { Observações do } \\
\text { pesquisador }\end{array}$} \\
\hline & 1 & 2 & 3 & 4 & 5 & 6 & 7 & 8 & 9 & 10 & 11 & 12 & \\
\hline $\begin{array}{l}\text { Condução e correção, } \\
\text { na lousa ou através de } \\
\text { um computador e } \\
\text { datashow, } \\
\text { traduções apresentadas } \\
\text { oralmenter pelos } \\
\text { alunos, tomando como } \\
\text { base suas próprias } \\
\text { opiniões enquanto } \\
\text { professor e tradutor } \\
\text { profissional. }\end{array}$ & & & & & & & & & & & & & \\
\hline
\end{tabular}

Elaboração: Marileide Dias Esqueda

As aulas do contexto investigado têm duração de três horas, isto é, 180 minutos. Portanto, dividiu-se a aula em 12 períodos de 15 minutos. Como mencionado, evitando-se um alto grau de inferência ou julgamentos durante as observações, principalmente porque há uma tendência inevitável de o pesquisador se concentrar em aspectos negativos durante as sessões de observações (BIAZI; GIMENEZ; STUTZ, 2011; NODARI; ALMEIDA, 2012), o instrumento assim organizado propiciou que se marcasse com um " $x$ " a natureza da ação do professor e sua frequência, conforme será mostrado nos resultados.

Para que a pesquisadora se tornasse proficiente no manejo das categorias, o protocolo foi elaborado cerca de dois meses antes da coleta dos dados e testado em disciplinas ministradas por docentes do mesmo contexto de investigação, principalmente para se averiguar o número de categorias, se elas não se sobrepunham e se estavam de acordo com o tempo gasto normalmente pelos professores durante a exposição de conteúdos teóricos e práticos da sala de aula de prática de Tradução. O pré-teste das observações também foi importante para que a pesquisadora pudesse estar ciente de seu lugar em sala de aula, isto é, para caracterizar os efeitos de escolher sentar-se em uma carteira localizada em um dos cantos da sala, evitando o contato visual direto com o professor e para que não houvesse a intenção de intimidá-lo, primando pelo comportamento menos intrusivo possível e assim não violando quaisquer princípios éticos. Como já averiguado empiricamente em outros estudos, os professores consideram a observação como uma crítica a seu trabalho e temem o julgamento (BIAZI; GIMENEZ; STUTZ, 2011; NODARI; ALMEIDA, 2012).

Vale ressaltar que não se tratou de identificar, durante as observações, se existem abordagens certas ou erradas, e tampouco as etapas anteriores desta pesquisa se prezaram a isso, 
mas de compreender as abordagens adotadas pelos professores em contextos reais de ensino e aprendizagem de Tradução e suas eventuais necessidades. Para González-Davies (2004, p. 1314), à principal abordagem pedagógica adotada por um professor de tradução podem ser acrescentadas outras abordagens igualmente válidas e relacionadas à aquisição de línguas, de noções culturais, cognitivas, funcionalistas ou filosóficas, a depender de como o professor concebe os textos e suas traduções, inexistindo uma única e infalível abordagem.

As aulas foram observadas durante um mês, tempo suficiente para se confirmar a hipótese através desse tipo de protocolo de observação estruturada, com categorias já estabelecidas. No entanto, para se estudar mais a fundo as interações de sala de aula, pode-se afirmar que esse tempo é insuficiente, principalmente quando se trata do tipo de observações participantes, em que as categorias não estão estabelecidas e surgem à medida que as sessões de observações ocorrem. Dito de outra maneira, o instrumento de observação estruturada como o que foi adotado para essa etapa da pesquisa destina-se à confirmação de hipótese.

Quanto ao número de docentes envolvidos, via de regra, as pesquisas qualitativas têm como foco um número reduzido de participantes, tendendo a explicar seu repertório e descobrir o que é semelhante e o que é diferente na comparação com contextos distintos (COHEN et al., 2018, p. 647). Assim, do quadro de aproximadamente 20 professores permanentes e 30 professores temporários contratados em tempo parcial na universidade canadense investigada, cinco professores responsáveis por disciplinas de prática da Tradução foram convidados para participar da pesquisa, isto é, por amostragem dispersa (FLORES, 2003). Após serem informados a respeito dos propósitos da investigação, os professores assinaram o Termo de Consentimento Livre e Esclarecido (TCLE), aceitando fornecer respostas aos questionários e às perguntas da entrevista e permitindo a observação de suas aulas durante um mês, a contar do primeiro dia de aula.

Como forma de gestão mais proveitosa dos resultados, o questionário e a entrevista respondidos pelos professores canadenses serão expostos e comparados, sequencialmente, aos dados oriundos dos participantes brasileiros, investigados nas primeira e segunda etapas. Os resultados das observações de aulas não serão comparados ao contexto brasileiro, para o qual não se implementou esse tipo de instrumento. Os resultados oriundos das observações de aula serão quantificados e analisados de forma a corroborar a hipótese do estudo. 


\section{Perfil e abordagens pedagógicas de professores de Tradução: comparando os contextos canadense e brasileiro}

\subsubsection{Resultados do $Q 1$}

Como forma de preservar a identidade dos participantes, cada professor entrevistado na universidade canadense corresponde, no relato dos dados, à letra "P" acompanhada de um número de 1 a 5 . Os 5 docentes receberam o Q1, foram entrevistados e tiveram suas aulas observadas durante um mês.

Com relação ao Q1, dos cinco participantes, com idade média entre 35 e 57 anos, dois possuem Licenciatura em Letras, um é graduado em Estudos Latino-Americanos, outro em Estudos Hispânicos e um em Administração. Com relação à formação em nível de mestrado, os cinco participantes possuem mestrado ${ }^{11}$ em Tradução. Com relação à formação em nível de doutorado, apenas um possui o título de doutor, sendo que três são doutorandos e um deles iniciou seus estudos em nível de doutorado, sem, no entanto, concluí-los.

A média de experiência dos participantes com o ensino de Tradução é de seis (6) anos,

144 sendo que P1 possui 19 anos de experiência no ensino de Tradução e P5 de aproximadamente um ano.

Quando indagados se fazem parte de alguma associação, grupo de pesquisa ou fóruns on-line da área de Tradução, a maioria afirmou não participar de nenhum desses tipos associações ou grupos. Apenas um deles mencionou fazer parte da OTTIAQ (Ordre des traducteurs, terminologues et interprètes agréés du Québec), CATS (Canadian Association for Translation Studies), HISTAL (Grupe de Recherche sur l'historie de la Traducción en Amérique Latine) e da comunidade Young Translation Studies Scholars da rede social on-line Facebook.

Assim como em contexto brasileiro, os cinco professores entrevistados têm perfil diversificado em relação à área de formação, idade e ao tempo de docência no ensino de Tradução, o que evidencia a ausência de uma prática docente equalizada para o ensino de Tradução e a não incorporação sistematizada dos avanços teóricos e científicos à Pedagogia da Tradução em sala de aula. Além disso, pode-se inferir que os professores não estão encontrando nas associações ou fóruns o respaldo necessário para sua atividade profissional e tampouco para a docência, assim como revelaram os dados em contexto brasileiro.

$100 \%$ dos docentes canadenses afirmaram ter experiência profissional em tradução, sendo que o fato de serem tradutores e intérpretes e fazerem parte do mercado real de trabalho 
concede, na visão deles, mais credibilidade junto aos alunos e valida seus discursos. P5, no entanto, acrescentou que as informações do mercado real não necessariamente formam os futuros profissionais. Para esse participante, a formação de tradutores está centrada na ideia de ensinar os alunos a compreenderem o processo de tradução.

Embora apenas um dos participantes tenha mencionado a importância acerca do ensino centrado no processo tradutório, a maioria dos docentes entrevistados, assim como em contexto brasileiro, atribui ao saber prático, ou disciplinar, isto é, aos saberes sobre a profissão de tradutor, grande importância, sem mencionar os demais saberes do professor. Para Pimenta (2016), os saberes da docência envolvem não apenas os saberes profissionais, isto é, os específicos do profissional e dos conhecimentos da área de sua especialidade, mas também os saberes pedagógicos, que abrangem a construção de ações pedagógicas em sala de aula, a partir das necessidades dos alunos; os saberes curriculares, relativos à transformação dos conteúdos em disciplinas e programas de ensino; e os saberes experienciais, que são mobilizados a partir do universo de experiências (pessoais e profissionais) do professor, exigindo da atividade uma constante reflexão e reconfiguração. A autora afirma que a fragmentação entre os diferentes saberes do docente deveria ser superada, considerando a importância da ressignificação dos saberes na formação dos professores.

\subsection{Resultados das entrevistas estruturadas (contexto canadense) em comparação com o Q2 (contexto brasileiro)}

No que se refere às entrevistas estruturadas, como já explicitado, buscou-se organizar suas questões de modo que aquelas de simples resposta fossem alocadas para o início e fim da entrevista, deixando aquelas de maior complexidade e interesse para a pesquisa para metade do tempo destinado à entrevista.

As respostas dos professores canadenses para a pergunta "Em sua opinião, qual é a importância da sua disciplina para o programa de Tradução de sua universidade?" (In your opinion, what is the importance of your course to the university program?) não são semelhantes. Um participante afirmou que sua disciplina não é importante porque é optativa para o currículo do curso, outro afirmou que sua disciplina existe porque a universidade quer responder às necessidades do mercado de trabalho. P3 descreveu que sua disciplina prepara o aluno para a escolha de métodos de trabalho para se abordar um texto. P2 explicou que sua disciplina, que aborda a tradução de textos gerais, é importante porque nunca viu um curso de Tradução dar início ao componente prático de tradução por meio de textos difíceis, como os da área da 
Literatura, por exemplo. P4 afirmou que sua disciplina é importante para despertar a consciência dos alunos acerca dos problemas da tradução.

Com relação à pergunta "Quem decide sobre o conteúdo de sua disciplina" (Who decides about the syllabus of your course?), por um lado, 100\% dos participantes afirmaram ter liberdade para decidir sobre o conteúdo da disciplina, por outro, também foram unânimes em afirmar que não recebem orientações suficientes da instituição para planejar suas disciplinas. Um deles afirmou que sabe que os conteúdos abordados em sua aula muitas vezes se repetem em aulas de outros docentes. P2 apontou que sempre recebe o plano de ensino apenas com os campos a serem preenchidos e que a instituição não possui um banco de dados que possa servir como base para recuperar o conteúdo trabalhado por outro professor que já tenha ministrado a disciplina. P1 respondeu que escolhe as traduções de textos que ele gosta ou tem afinidade, sendo que outro participante escolhe seus textos de jornais ou revistas. P5 afirmou que a instituição não o guia na elaboração do plano de ensino e, portanto, ele opta por abordar a gramática em sala de aula de prática de tradução para aprimorar as habilidades linguísticas dos alunos.

Assim como em contexto brasileiro, e também nos achados de Darin (2001), constatase a ausência de diretrizes pedagógico-metodológicas comuns na sala de aula de tradução no contexto canadense investigado, não havendo consenso sobre o modo como os textos poderiam ser escolhidos e abordados e em sala. Com relação aos textos de jornais ou revistas, Nord (2000) explica que:

[...] selecionar textos para aulas de tradução não é uma questão de aderir a princípios rígidos, tampouco mera intuição. É requisito fundamental do ensino de tradução que apenas textos autênticos sejam usados como materiais, isto é, textos reais, e que sejam relevantes para a prática. Isso significa que em um país como a Alemanha, onde os artigos de jornais quase nunca são traduzidos porque os grandes jornais têm seus próprios correspondentes em todo o mundo, textos jornalísticos desempenham um papel secundário nas aulas de tradução, se é que tem alguma validade - eles podem ser bastante úteis quando se deseja lidar com problemas de tradução evolvendo realidades culturais ou outras alusões. Todos os textos-fonte devem ser apresentados aos alunos de tal forma que seja fornecida a eles a maior quantidade possível de informações sobre a situação em que o original é ou foi usado, a fim de tornar a tarefa mais realista. (NORD, 2000, p. 38, tradução nossa) ${ }^{12}$

Para aliviar a carga de informações da entrevista, as perguntas 3, 4 e 5 da entrevista abordam questões igualmente gerais: “A sala onde ocorre sua disciplina é adequada para seus propósitos pedagógicos?” (Is the room (place) of your course adequate for its pedagogical purposes?); "Você acha que consegue abordar todo o conteúdo necessário de sua disciplina em 
um trimestre?" (Do you think you can cover the necessary content of your course in one trimester?); "O número de alunos influencia a forma como você ensina?" (Does the number of students influence the way you teach?).

Com relação à pergunta $3,100 \%$ dos participantes responderam que as salas de aula são adequadas ao ensino e são bem equipadas, porém a fixidez de mesas e carteiras dificulta o trabalho em grupo e a mobilidade do professor. Um participante acrescentou que sua disciplina deveria ocorrer em um laboratório de tradução, propiciando aos alunos o uso do computador.

Embora essa seja uma pergunta geral, não significa que sua resposta não tenha importância. Kelly (2005) dedica cerca de três seções de sua obra para discutir a questão da disposição física das salas de aula e laboratórios de tradução, além de também analisar em que medida os recursos tecnológicos interferem na formação de tradutores. Para a autora, a organização física de uma sala de aula nos fala muito sobre as abordagens de ensino adotadas. Alunos sentados em fila, olhando para o professor, que tem um lugar central, muitas vezes até em uma plataforma elevada, onde se pode sentar e dirigir aos ouvintes, implica a adoção de uma abordagem fortemente transmissionista, centrada no professor e provocando a conferência magistral. Neste contexto, os alunos não são estimulados a compartilhar seus conhecimentos e o que estão aprendendo e os professores têm dificuldades de pensar em como romper com os métodos transmissionistas de ensino (KELLY, 2005, p. 81).

No que concerne à pergunta $4,100 \%$ dos participantes afirmaram que um trimestre é suficiente apenas para introduzir o assunto da disciplina e que é preciso que o professor faça muitas escolhas para abordar o conteúdo. Um participante acrescentou que tudo depende do que a instituição deseja para formação do aluno.

Todos os participantes afirmaram que o número de alunos influencia a forma de ensinar e que o que fica mais comprometido no ensino da Tradução dirigido a classes numerosas é a avaliação. Para os participantes, torna-se impossível avaliar com frequência todos os alunos. Uma das maiores preocupações dos entrevistados desse contexto diz respeito ao número excessivo de alunos em sala, que às vezes ultrapassa 50. Para Kelly (2005), quanto maior o número de alunos, maior o risco de adoção de uma abordagem nos moldes transmissionistas e convencionais, que prevê a passividade dos alunos e de estes deixarem o ambiente universitário fazendo muito pouco por sua própria aprendizagem.

Com relação às perguntas centrais da entrevista, e que visam corroborar a hipótese de pesquisa de que a fórmula pedagógica da performance magistrale ainda não foi banida do ensino da Tradução, assim como em contexto brasileiro, os participantes, ao responderem à 
pergunta “Como você descreveria suas típicas aulas de prática de tradução?” (How would you describe your typical translation practice courses), quatro dos cinco participantes afirmaram que:

- as aulas se iniciam com uma explicação da sequência das atividades do dia;

- em seguida tiram-se as dúvidas dos alunos da aula anterior (se for esse o caso);

- há contextualização do assunto em nível teórico e leitura de excertos importantes do texto teórico em análise;

- na sequência, apresenta-se o texto a ser traduzido em sala e discutem-se seu gênero, suas dificuldades, sua formatação, seu vocabulário;

- a tradução é encomendada parte para a sala de aula e parte para ser feita extraclasse;

- ouvem-se as opções dos alunos e o professor as discute;

- em seguida, o professor mostra, geralmente utilizando um datashow, a tradução publicada do texto (quando existe), ou uma tradução que o professor detém;

- como atividade extraclasse, o aluno deverá finalizar a tradução;

- em aula posterior, os alunos leem excertos do texto traduzido para o professor e colegas; alguns alunos são sorteados para a apresentação oral de suas traduções, podendo a tradução do aluno ser exibida pelo projetor da mesa do professor a todos os demais;

- o professor discute as opções dos alunos, avaliando a consistência terminológica do texto;

- a aula geralmente termina com o professor solicitando a finalização do texto a ser realizada extraclasse.

De forma geral, a performance magistrale ainda é utilizada como fórmula pedagógica predominante, conforme relatam os quatro participantes. Nesses moldes, o professor busca avaliar a consistência e o conteúdo correto dos textos traduzidos com base em suas avaliações pessoais e com base nas traduções publicadas existentes. Os docentes entrevistados mostram, de maneira geral, que adotam atividades convencionais, nas quais se realizam a leitura do texto original, a sua tradução preliminar de forma oral, a elaboração da tradução pelos alunos em intervalo de tempo pré-estipulado, durante o qual os alunos devem aprender a traduzir traduzindo e, por último, a posterior verificação das opções de tradução junto a todos os alunos; outros professores agregam a essa prática outras atividades que, no entanto, são implementadas 
à rotina pedagógica de maneira isolada e assistemática, tal qual em contexto brasileiro. Vale ressaltar também que três dos cinco professores mencionam utilizar como aporte teórico o texto de Delisle (2013), apenas por saber que todos os alunos têm a obra e seria mais fácil utilizá-la em lugar de outra.

No caso do quinto participante, que relatou utilizar a abordagem baseada em problemas (em referência ao termo em inglês, problem-based learning), sua rotina didática assemelha-se à sequência seguida pelos demais professores. Segundo esse participante, o conteúdo e a sequência da aula são apresentados aos alunos para que eles tenham uma ideia do que irão estudar naquele dia, em seguida tiram-se as dúvidas da aula anterior, ou de alguma atividade realizada ou a ser realizada pelos alunos; tem-se, subsequentemente, a discussão dos problemas de tradução colocados pelo professor aos alunos, sendo fornecido um intervalo de tempo para que os grupos busquem formas de solucionar os problemas. Depois de transcorridas tais etapas, o professor solicita que os grupos apresentem as soluções para os problemas, discutindo, após isso, os achados dos alunos. A aula geralmente termina com o professor fornecendo as orientações para a finalização, extraclasse, das formas de solução dos problemas tradutórios.

O diferencial dessa abordagem baseada em problemas é que a presença física dos alunos em sala de aula é bastante valorizada, possibilitando que, ao trabalharem em pequenos grupos, possam intercambiar ideias e conhecimentos. Outro diferencial dessa abordagem, que surge nos anos 1980 no contexto de ensino da Medicina, Arquitetura e Direito (CORMIER, 1998), é que o professor atua como facilitador da aprendizagem, aguardando que os alunos solucionem os problemas reais da tradução a eles propostos, cujos conhecimentos acerca de tais problemas não lhes foram apresentados previamente, mobilizando sua aprendizagem.

Para a pergunta número 7 "Dentre as abordagens pedagógicas: “abordagem por objetivos", "abordagem por competências", “abordagem por tarefas", "abordagem por problemas", "abordagem por projetos", "abordagens por estudo de caso", "abordagem colaborativa" ou outras, qual(is) dela(s) você utiliza em sala?" (In relation to the teaching approaches such as "teaching objectives", "competence-based approach”, "task-based approach", "problem-based approach”, “case study approach”, “collaborative approach”, which one do you usually follow in your classes?"), as respostas foram divergentes e também contraditórias. P3 respondeu utilizar a abordagem por objetivos, centrando-se na obra de Delisle (2013); P2 afirmou utilizar uma abordagem por estudo de caso, buscando trazer elementos do mercado real de trabalho e o caso de certos clientes com os quais o docente já trabalhou para ilustrar suas aulas. P5 afirmou fazer uma conexão entre todas as abordagens. P4 afirmou utilizar 
a abordagem baseada em problemas, por ter sido a indicação de um outro docente do departamento e, por último, P1 afirmou não saber que abordagem utiliza, e que seu maior problema é nem saber que elas existem. Embora divergentes, tais respostas não se coadunam com as respostas da pergunta anterior e tampouco com os dados provenientes da observação de aulas que serão relatados a seguir. No caso das respostas à pergunta anterior, os professores expressam seguir uma sequência de aula que não parece estar coerente com a abordagem que nomeiam ou dizem utilizar. Dito de outra forma, a típica abordagem pedagógica que descrevem na pergunta 6, que se evidencia como a fórmula da performance magistrale, está em desacordo com a escolha do tipo de abordagem que selecionaram na pergunta 7. Apenas um dos cinco docentes nomeia, de fato, a abordagem que utiliza, a abordagem baseada em problemas, fazendo uso efetivo desta em sala de aula junto a seus alunos, muito embora a eficácia dessa abordagem para a aprendizagem ainda demande investigações de caráter empírico conduzidas especificamente nos Estudos da Tradução ${ }^{13}$ (CORMIER, 1998; GAMBIER, 2012).

Com relação aos critérios de avaliação das traduções realizadas, para a pergunta número 8 "Você segue algum critério ou sistema de avaliação para avaliar as traduções entregues por 150 seus alunos e para as provas?" (Do you follow any rubrics or criteria to evaluate your students, translations and exams?), três dos cinco participantes afirmaram considerar a qualidade linguística dos textos traduzidos como o critério mais importante do sistema de avaliação, ao passo que dois participantes relataram que penalizam seus alunos se eles não seguirem as instruções dadas em sala de aula, principalmente quanto ao público-alvo definido para o texto a ser traduzido, onde será possivelmente publicado, e se os aspectos textuais mais importantes do texto não foram seguidos. Embora possa-se afirmar que os participantes vislumbram em seus sistemas de avaliação não apenas o texto, mas também a quem é dirigido, quando e onde será publicado, a maioria dos docentes penaliza seus alunos pelos erros linguísticos cometidos no texto. Critérios de avaliação centrados no aluno ou autoavaliação não foram relatados pelos participantes, como também ocorre em contexto brasileiro. Para Gile (2009), o ensino da tradução necessita melhor prever em que fase do processo de ensino e aprendizagem os professores deverão avaliar o processo, e em que fase deverão avaliar o produto. Para o autor, as fases iniciais de formação devem focar a avaliação do processo, isto é, como um tradutor em formação pode aprender a utilizar recursos para elaborar uma boa tradução, fato este também destacado por Fiola (2003b, p. 225). O que emerge dos dados dessa pergunta, tanto em contexto brasileiro quanto canadense, que o foco da avaliação da maioria dos docentes recai sobre a qualidade linguística do produto final, não importando o estágio de aprendizagem dos alunos. 
Para a pergunta "O que define um bom professor de tradução?" (What defines a good translation teacher?), as respostas dos participantes dos contextos brasileiro e canadense são semelhantes:

Quadro 2 - Respostas dos participantes brasileiros e canadenses à pergunta "O que define um bom professor de tradução?"

Participantes do contexto brasileiro Participantes do contexto canadense

O BOM PROFESSOR DE TRADUÇÃO É AQUELE QUE....

- corrige os erros, mas também aponta os aspectos positivos das traduções dos alunos;

- tem autoridade para corrigir os alunos por ser um tradutor reconhecido; o professor que é tradutor premiado (no setor editorial) sabe dominar a sala de aula;

- revisa o texto com os alunos, verificando se estão progredindo ou se continuam cometendo os mesmos erros;

- $\quad$ percebe as limitações dos alunos.
- $\quad$ sabe mostrar aos alunos onde estão os erros e como solucioná-los;

- deve usar sua experiência como tradutor para guiar os alunos;

- deve mostrar aos alunos como eles podem aprender;

- sabe respeitar os alunos como seres humanos.

Elaboração: Marileide Dias Esqueda.

Além dessas características atribuídas ao professor de Tradução de ser tradutor profissional para poder corrigir seus alunos, P1 acrescentou que o bom professor de Tradução deve fazer a tradução do texto antes de solicitá-la aos alunos, prevendo todos os seus problemas, revelando, mais uma vez, o "complexo de Atlas" citado por Colina (2015). Para a autora, os professores não são "Atlas" que carregam em seus ombros a inteira responsabilidade pela identificação e solução de todos os problemas tradutórios, pois os estudantes não são passivos receptores de conhecimento, mas participantes ativos no processo de aprendizagem. Os professores necessitam se ver como facilitadores que podem fornecer recursos adequados, permitindo aos estudantes avançarem da maneira mais eficiente possível durante o processo de aprendizagem. Como especialistas, os professores podem facilitar a aprendizagem, encurtar o caminho e criar o ambiente adequado e condições para o desenvolvimento dos vários aspectos que permeiam os textos e suas traduções.

No que tange à forma como os docentes de Tradução definem seus saberes, ressalta-se que dois dos cinco participantes mencionaram que o professor de Tradução deve conhecer muito bem o conteúdo de sua aula, dois docentes acreditam que o professor de Tradução deve ser um bom comunicador e humilde o suficiente para aceitar o ponto de vista dos alunos, e um 
ressaltou que o bom professor de Tradução deve ter conhecimento linguístico acima de qualquer outro.

Para a pergunta "Descreva o pior e o melhor professor que você já teve" (Can you describe the best/worst teacher you ever had?), 100\% dos participantes afirmaram, de um lado, que o melhor professor que tiveram respeitava os alunos e aceitava seus erros. P1 ainda relatou que seu melhor professor estava preparado para dar aulas, já que as práticas de tradução não podem ser improvisadas. P2 e P3 acrescentaram que o melhor professor que tiveram tinha experiência como tradutor e critérios claros para julgar suas traduções. P4 acrescentou que seu melhor professor mostrava-lhe a utilidade das coisas para o mundo real. De outro lado, 100\% dos participantes afirmaram que o pior professor que tiveram humilhava os alunos, expondo-os diante de toda a classe. P4 acrescentou que, além disso, o pior professor que teve estava centrado nele mesmo, e discursava em aulas por mais de três horas, como se os alunos não estivessem na sala. P5 acrescentou ainda que o pior professor que teve matava o "espírito" dos alunos.

Assim como em contexto brasileiro, todos os participantes do contexto canadense condenam a relação assimétrica de forças em sala de aula, porém suas práticas, como se pode constatar nas respostas anteriores e como poderá ser constatado nos dados provenientes das observações de aulas, ainda é bastante influenciada pelos professores que os antecederam. Além disso, os professores tentam desenvolver e se espelhar em práticas racionais em sala de aula, tanto em contexto brasileiro quanto canadense, mas a dimensão afetiva e emocional continua na base do ensino.

Findas as perguntas mais complexas da entrevista (COHEN et al., 2018), as quatro últimas perguntas tratam de buscar respostas quanto às necessidades reais e de formação dos docentes do contexto canadense, e que dizem respeito ao questionário prospectivo da segunda etapa da pesquisa, de caráter longitudinal, aplicado no contexto brasileiro.

Com relação à pergunta "Você acredita que a formação contínua do professor de Tradução é importante?" (Do you think in-service training programs are important?), 100\% dos participantes manifestaram interesse pela formação contínua, considerando-a essencial, o que revela o compromisso dos docentes com o seu processo de desenvolvimento profissional, respostas essas que são idênticas as dos participantes brasileiros.

Ao serem indagados sobre quais tipos de cursos de formação contínua poderiam melhorar suas aulas (What kind of in-service training programs for teachers would better improve your classes), os cinco professores afirmaram que gostariam de participar de workshops (ou cursos/oficinas práticas) que lhes orientassem como ensinar determinados temas 
aos alunos. Para os participantes, a universidade apenas lhes entrega um plano de curso ainda a ser construído e não lhes fornece quaisquer orientações sobre como ensinar, como escolher os textos, como abordar alunos com deficiências físicas ou necessidades especiais. $100 \%$ dos participantes desejam workshops ou reuniões formais com seus pares para se aprimorarem e terem ciência do que o outro professor está ensinando aos alunos. As respostas para essa pergunta se assemelham às aspirações dos docentes brasileiros, que veem nos workshops (ou cursos/oficinas práticas) destinados à elaboração de materiais uma forma de aprimoramento da prática pedagógica, embora, em contexto brasileiro, o manejo em sala de aula das novas tecnologias da tradução esteja no centro das preocupações dos professores.

Quando indagados quais tópicos são mais fáceis e difíceis de serem trabalhadas em sala, dois dos participantes consideram a prática de tradução mais difícil, podendo-se inferir que a formação que o professor recebe nos programas de mestrado e doutorado em Tradução parece suprir formas de ensino da teoria, em detrimento de sua articulação com a prática. Com relação ao restante dos participantes, um deles afirmou que o mais difícil é ensinar o elo entre teoria e prática, P5 respondeu que é ensinar aos alunos como utilizar suas habilidades cognitivas para pensar nas soluções tradutórias; P1 respondeu que o mais difícil é ensinar os alunos a importância da participação deles em sala da aula. Dois docentes também acrescentaram às informações anteriores que o que é mais fácil é ensinar aos alunos como utilizar o dicionário ou outros recursos. Assim como ocorre com os professores brasileiros de Tradução, os dados mostram o anseio por aprimorar formas de ensino das relações teóricas e práticas da tradução. Sobre essa relação, pode-se inferir que a tensão entre as várias correntes teóricas existentes nos Estudos da Tradução, seus vários modos de conceber as modalidades de tradução podem ser impactantes e desestabilizam as práticas de sala de aula.

Com uma média de 14 anos de experiência docente entre os professores brasileiros e 6 anos entre os professores canadenses, os participantes de ambos os contextos estão, em sua maioria, em fase de estabilização da carreira, sendo P5 do contexto canadense o único que se encontra na fase do "choque do real e da descoberta" (HUBERMAN, 1995 apud GIORGI et $a l ., 2010)$, com apenas um ano de experiência docente. Os professores, tanto do Brasil quanto do contexto canadense investigado, têm clara compreensão sobre quais áreas precisam e querem aprimorar. Cabe às instituições, em parcerias com seus professores, pensarem em novas formas de desenvolvimento docente, que lidem com os reais problemas dos professores. O que se pode inferir em ambos os contextos é que os professores trabalham longe das vistas de seus colegas e da própria instituição, formando-se e aperfeiçoando-se, na medida do possível, na própria sala 
de aula, sem pouco ou nenhum contato com seus pares. As palavras de um dos participantes do contexto canadense podem resumir tal situação: “Don't ask me to play Jesus. I have lots of students. The faculty members need to connect the dots. I need some help". [sic.] ("Não me peça para bancar o Jesus. Tenho muitos alunos. A instituição tem que "ligar os pontos". Preciso de ajuda). Para Feiman-Nemser (2001), oportunidades constantes de diálogos substanciais entre professores os ajudam a superar o isolamento. Nas palavras da autora, o que define a formação contínua é, além do apoio de colegas locais, o acesso a uma comunidade de discurso mais ampla sobre a área em que se atua para que as pedagogias de fato se transformem.

\subsection{Resultados das observações de aulas}

Foram observadas as quatro primeiras semanas de aula (um mês) dos cinco participantes da pesquisa em sua terceira etapa. Considerou-se importante iniciar as observações a partir do primeiro dia de aula em diante, uma vez que, geralmente, os professores estabelecem suas diretrizes de condução das aulas junto aos alunos neste dia, expondo as leituras e atividades obrigatórias e seu sistema de avaliação. Nesse sentido, o papel que o professor assume e as

154 atividades que elabora influenciam o papel dos seus alunos e circunscrevem a abordagem pedagógica.

Quando das observações de aula, marcou-se com um "x", a cada 15 minutos, as ações tomadas pelo professor em sala de aula com frequência mais evidente. Não foram descritos quaisquer eventos isolados ou assistemáticos. Após realizar todas as observações e determinar a prevalência de uma ou mais categorias durante as aulas dos cinco participantes, transformouse, como descrito no quadro a seguir, o número de vezes em que determinada categoria foi assinalada com " $x$ ", que equivale a 15 minutos, no total de minutos. Para as demais categorias que tiveram uma prevalência menor que 15 minutos, marcou-se o número aproximado de tempo a elas dedicadas e não foram marcadas (--) as categorias que, embora possam estar presentes na rotina pedagógica do professor, duraram menos de cinco minutos. Subsequentemente, foi encontrada a média do tempo gasto pelo professor em determinadas categorias durante as aulas observadas, como mostra o quadro a seguir. 
Quadro 3 - Frequência média em minutos da ação dos participantes nas aulas observadas

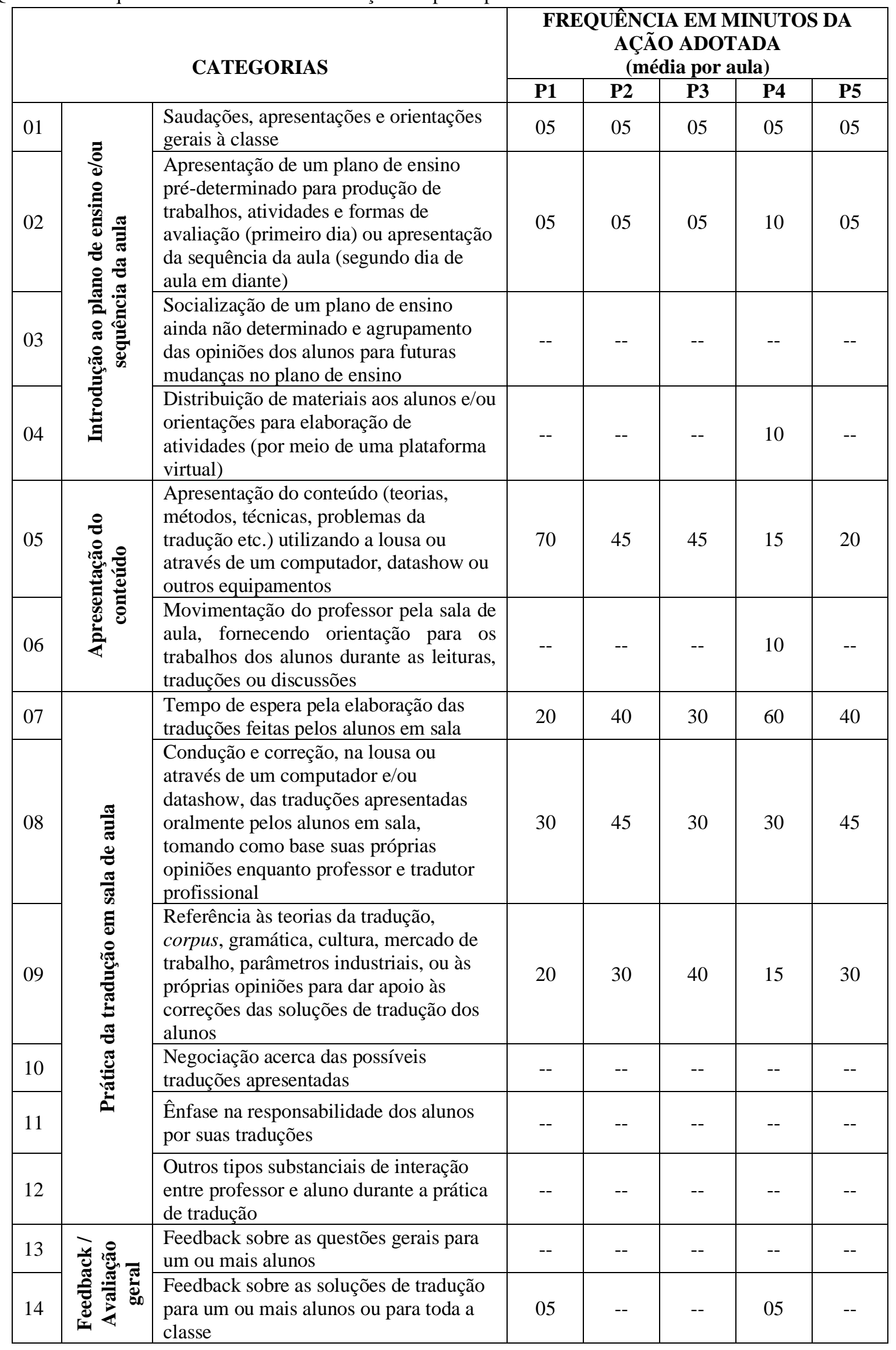




\begin{tabular}{|c|c|c|c|c|c|c|c|}
\hline 15 & & $\begin{array}{l}\text { Elaboração em voz alta de perguntas aos } \\
\text { alunos acerca das justificativas para as } \\
\text { soluções de tradução (não retóricas) }\end{array}$ & 05 & -- & 05 & -- & 10 \\
\hline 16 & & $\begin{array}{l}\text { Elaboração em voz alta de perguntas aos } \\
\text { alunos acerca das justificativas para as } \\
\text { soluções de tradução (retóricas) }\end{array}$ & -- & -- & -- & -- & 05 \\
\hline 17 & 总 & $\begin{array}{l}\text { Orientações gerais à classe sobre a } \\
\text { entrega das traduções (após } \\
\text { revisão/correção/identificação de } \\
\text { problemas); }\end{array}$ & -- & -- & 05 & 05 & -- \\
\hline 18 & $\stackrel{\bar{\omega}}{\overrightarrow{0}}$ & $\begin{array}{l}\text { Referência aos exames finais e outras } \\
\text { orientações }\end{array}$ & 05 & -- & -- & -- & 05 \\
\hline \multicolumn{8}{|c|}{ Intervalo de 15 minutos } \\
\hline \multicolumn{3}{|c|}{ Duração total da aula (em minutos) } & 180 & 180 & 180 & 180 & 180 \\
\hline
\end{tabular}

Elaboração: Marileide Dias Esqeuda

O quadro 3 apresenta, na coluna 1, os números das categorias estabelecidas para o protocolo, na coluna 2 a descrição das possíveis fases de uma aula, que partem do momento em que o professor entra em sala, introduzindo a aula e apresentando sua sequência, até as orientações gerais, em que finaliza a aula fazendo referência aos eventos das semanas seguintes 156 ou a provas e exames. A terceira coluna descreve mais detalhadamente a ação em 18 categorias. Da quarta a oitava coluna estão descritos os tempos em minutos da prevalência da ação tomada pelos professores, de P1 a P5.

Os dados ilustram, a partir da representação visual numérica do quadro, como se caracterizam as aulas de cinco professores de Tradução do contexto canadense investigado.

Os docentes gastam em média de cinco a dez minutos para cumprimentar seus alunos, fornecer informações gerais quanto às atividades de sala ou outros e apresentar a sequência da aula, marcados nas categorias 1 e 2 . Nenhum professor buscou socializar o plano de ensino e a dinâmica das aulas com seus alunos (categoria 3) e, 100\% dos professores utilizam uma plataforma de gerenciamento de cursos (em inglês, course management system) como apoio à aula presencial, que disponibiliza on-line o plano de ensino, cronograma de atividades, arquivos diversos contendo os conteúdos das aulas e os textos teóricos. Portanto, pouco ou quase nenhum tempo das aulas é gasto com distribuição de materiais. No entanto, a rotina de P4 revela um gasto de 10 minutos em média por aula para distribuição de materiais. Os outros quatro professores também distribuem textos a serem traduzidos pelos alunos, em folhas avulsas, porém tais ações têm duração menor que cinco minutos. Essas folhas avulsas contêm normalmente um texto de 100 a 200 palavras que deverão ser traduzidas em sala. Esses dados 
diferem dos relatos dos professores brasileiros, que afirmam solicitar textos de 280 a 350 palavras a serem traduzidos por seus alunos.

Pode-se visualizar a maior prevalência do tempo gasto pelos professores em sala de aula nas categorias 5, 7, 8 e 9. Dito de outra maneira, o ensino da Tradução em disciplinas práticas centra-se, no contexto canadense, basicamente na apresentação do conteúdo e problemas da tradução, que leva em média 40 minutos, sendo que P1 gasta cerca de 70 minutos e P4 gasta 15 minutos, no tempo de espera para que os alunos traduzam os textos em sala, que dura cerca de 38 minutos, em que P1 gasta 20 minutos e P4 60 minutos, na correção dessas traduções a partir da fórmula da performance magistrale, isto é, o aluno lê a tradução que ele fez em sala e o professor a comenta, fazendo correções, cuja média é de 36 minutos, sendo que dois docentes gastam cerca de 45 minutos e três 30 minutos, e em média 27 minutos utilizando geralmente referências relacionadas às estruturas gramaticas das línguas inglesa e francesa ou às próprias opiniões do professor para justificar as correções das traduções feitas pelos alunos. Outras justificativas são dadas pelo professor em relação às pesquisas oriundas da internet, parâmetros industriais ou ao público-alvo para corrigir as traduções, sendo que P3 gasta cerca de mais 40 minutos nesta categoria e, $\mathrm{P} 4,15$ minutos.

Não foram observados tipos significativos de negociação quanto às traduções apresentadas pelos alunos e tampouco houve ênfase à responsabilidade dos alunos quanto às traduções por eles apresentadas, relativos às categorias 10, 11 e 12, respectivamente.

Como já mencionado, um dos participantes adota a abordagem baseada em problemas. Embora possa ser adotada no ensino de Tradução como uma pedagogia alternativa, em substituição ao ensino transmissionista, que geralmente não sana as dificuldades dos alunos em relacionar a teoria à prática, estabelecer comparações com outras áreas do saber, e fazendo com que rapidamente se esqueçam do que lhes foi ensinado, desmotivando-os e tornando-os passivos, a abordagem baseada em problemas, segundo Cormier (1998), ainda carece de maiores estudos, principalmente em se tratando de seus reais efeitos na formação de tradutores ${ }^{14}$. No caso das observações realizadas na aula do docente que adota tal abordagem, percebe-se que alguns alunos, ao serem separados em grupos, pouco interagem com seus pares, recebendo passivamente as instruções daqueles colegas que "assumem o papel do professor" e impedindo-os mais uma vez de detectarem suas próprias necessidades de aprendizagem e de se tornarem autônomos (cf. FREITAS, 2012). Assim como Cormier (op.cit.), Gambier (2012, p. 166) também discute que: 
a utilização da dinâmica de grupo nem sempre ajuda todos os alunos da mesma maneira e nos mesmos níveis. Algumas questões ainda permanecem. Quando introduzir o trabalho em equipe no processo de aprendizagem? Como se certificar de que todos os alunos estejam motivados, ativos e trabalhando juntos e não uns contra os outros? (GAMBIER, 2012, p. 166, tradução nossa) ${ }^{15}$

Não houve prevalência de tempo gasto com o retorno formal e sistematizado das traduções corrigidas aos alunos (categorias 13 e 14) nas quatro primeiras semanas de aula. E as perguntas não retóricas (categoria 14), que poderiam ser uma forma de obter o feedback dos alunos quanto às atividades trabalhadas (categoria 15) também não tem prevalência significativa no contexto investigado. Em contrapartida, P5 gasta, em média, em todas as suas aulas, cerca de 5 minutos buscando feedback dos alunos por meio de perguntas retóricas, ou seja, em que o professor indaga os alunos e imediatamente responde às próprias indagações, propiciando pouca ou nenhuma chance de resposta dos alunos (categoria 16). Para Kelly (2005), para aprimorarem seus conhecimentos, os alunos precisam de feedback constante, que pode se configurar de várias formas, seja com instrumentos formais, informais ou até mesmo oralmente, dando-lhes a real chance de interação e avanço na aprendizagem.

Com relação às categorias 17 e 18 , pouco ou nenhum tempo é destinado ao fechamento das atividades desenvolvidas durante a aula. Embora P1 e P2 consigam finalizar com sucesso as propostas das aulas, P3 e P4 são os docentes que em média passam cinco minutos ressaltando a tarefa dos alunos para a aula seguinte. P5 geralmente não consegue finalizar a aula e as orientações quanto às tarefas das aulas seguintes são fornecidas de forma apressada em menos de um minuto, pelo menos nas aulas observadas. Quanto à categoria 18, P1 e P5, em média, fazem constantemente referências às avaliações e exames. P5 geralmente ressalta que seu objetivo não é amedrontar os alunos, mas ressaltar o fato de que eles devem se preparar para as provas finais. Infere-se, nesse caso, que a avaliação de traduções não está desvinculada da prova ou exame, revelando-se de orientação somativa. Dito de outra forma, os alunos receberam poucos elementos que propiciem a reorganização de suas aprendizagens na perspectiva da avaliação formativa preconizada por estudiosos que se dedicam ao tema (KELLY, 2005; COLINA, 2015; ECHEVERRI, 2015; 2018).

Para além dos números, os dados oriundos das observações também mostraram que:

- $100 \%$ dos participantes expuseram, no primeiro dia de aula, sua formação acadêmica e todos ressaltaram suas experiências como tradutores, possivelmente buscando justificar certo cabedal intelectual para o ensino da Tradução, o que 
fortalece o fato do saber profissional ser mais relevante que outros saberes na visão dos docentes canadenses, bem como como em contexto brasileiro, como já exposto;

- autores como Vinay e Darbelnet (1958), Seleskovich e Lederer (1989), e Delisle (2013) são alguns dos autores mais formalmente citados nas aulas práticas observadas, muito provavelmente porque a abordagem por objetivos do autor canadense Jean Delisle está baseada na abordagem teórica de Danica Seleskovich sobre a teoria interpretativa da tradução, ou, em francês, théorie du sens, e, também, devido à tradição canadense das análises contrastivas implementadas pelos autores Vinay e Darbelnet;

- três dos cinco participantes utilizaram textos jornalísticos e propagandísticos em suas aulas com extensão que varia, geralmente, de 100 a 200 palavras, revelando uma abordagem mais centrada nos problemas dos textos e não na aprendizagem (NORD, 2000);

- $100 \%$ dos participantes ressaltaram que a qualidade linguística e escolha de bons termos são as duas principais características de uma boa tradução; e

- quatro professores ressaltaram em suas aulas que o texto traduzido deve ser "natural", podendo-se inferir que traduzir se aprende traduzindo, diante da inexatidão do termo "natural".

Vale ressaltar que no caso da adoção e referência constante à obra de Delisle (2013) nas aulas observadas, Echeverri (2018) explica que:

Nenhum outro manual teve nem o impacto nem a influência que o manual de Delisle teve na formação de tradutores canadenses em quase 40 anos desde a publicação de sua primeira versão. Esta é uma boa indicação de como a formação de tradutores mudou muito pouco no Canadá. (ECHEVERRI, 2018, p. 31, nossa tradução) ${ }^{16}$

Centrada em um projeto político-social-linguístico, a Tradução, de acordo com o autor, é utilizada como ferramenta para defender o status e a qualidade da língua francesa, daí a justificativa de se utilizar a obra de Delisle que possui um enfoque comparativo, de modo a evitar e corrigir as interferências do inglês no uso da língua francesa no Canadá. Para Echeverri (2018), a obra de Delisle se fundamenta na "pedagogia preventiva" (em que se busca prevenir as interferências da língua inglesa na francesa), o que inevitavelmente traz consequências para o ensino da Tradução. 
Para finalizar, os professores seguem uma sequência de aula que não parece estar coerente com abordagem que selecionaram na pergunta 7 da entrevista, com exceção, mais uma vez, de P4, que utiliza e busca seguir os preceitos da abordagem baseada em problemas.

\section{Quais encaminhamentos poderiam ser propostos a partir daqui?}

A presente pesquisa, desmembrada em três grandes etapas, teve como proposta inicial, implementada em 2012, identificar o perfil de docentes de tradução em cenário brasileiro e as abordagens pedagógicas por eles adotadas; como proposta posterior, que ocorreu após um intervalo de cinco anos, em 2017, buscou-se examinar se a performance magistrale persiste ou se ocorreram mudanças nas abordagens pedagógicas em sala de aula e o que se mostra mais difícil e mais fácil de ser trabalhado com os alunos ainda com o mesmo grupo de participantes no Brasil. Na terceira e última etapa, realizada em 2019, buscou-se coletar parte dos mesmos dados junto a docentes de uma universidade canadense que oferta curso de Bacharelado em Tradução, com vistas a compará-los com a realidade brasileira.

Relata-se o fato de que enfrentar as dificuldades de uma pesquisa qualitativo-descritiva,

160 de cunho exploratório e longitudinal, que demandou o consentimento dos docentes brasileiros e a busca por esses após cinco anos, e da tão sistematizada quanto possível elaboração de um protocolo de observação de aulas para ser aplicado em contexto canadense, pareceu necessário para sustentar a ideia de que a investigação sobre o ensino da Tradução perpassa não apenas pela discussão do que deve ser ensinado, mas também pela atuação dos professores, que são atores de uma experiência acumulada que explica e detalha as respectivas realidades sobre a formação de tradutores.

Comparando os dois contextos, corrobora-se a hipótese de que as proposições teóricas, principalmente aquelas que se mostraram contra o ensino transmissionista, centrados no professor, que faz uso da performance magistrale, implementada desde há muito no ensino da tradução (ARROJO (1993); DARIN (2001); COLINA (2015); KELLY (2005); KIRALY (1995; 2000; 2014), ECHEVERRI $(2015 ; 2018)$ não têm sido suficientes a ponto de fazerem com que haja uma nova concepção sobre o ensino de Tradução em sala de aula. Atesta-se pouca variação no estilo de aula dos professores, muito embora, no caso das observações de aulas realizadas em contexto canadense, deva ser ressaltado o fato de que a forma como trabalham os docentes é sempre sensitiva a seu contexto, que nesse caso possui classes numerosas que pouco favorecem uma abordagem mais centrada no aluno. Dentre as várias consequências do ensino transmissionista, está o fato de a formação do tradutor permanecer centrada no produto, 
na transferência 1 para 1, correndo-se o risco de se assemelhar ao antigo método gramática e tradução.

Antes que se instale quaisquer preconceitos de que professores canadenses e brasileiros desconheçam seus ofícios, é importante mencionar que, embora os dados possam instalá-los no paradigma da performance magistrale, do "ler e traduzir", da conferência magistral (cf. nota de rodapé número 7), não se pode discriminar o que não aparece nas respostas ou o que não emerge das observações de aulas. Por detrás dos questionários, entrevistas, da duração e da frequência das categorias marcadas nas observações das aulas, não se pode deixar de mencionar as diversas atividades criativas planejadas pelos professores, comentários elucidativos, explicações extras e relatos de suas experiências profissionais extraordinárias. Os desafios metodológicos são inúmeros, no sentido de haver a necessidade de se aprimorar os instrumentos de pesquisa para poder averiguar a riqueza dos ambientes de ensino e aprendizagem de tradução. Apesar de seguirem confinados na sala de aula, aprendendo com as próprias dificuldades desse ambiente, os professores são produtores de conhecimento e se esforçam para encontrar subsídios pedagógicos, os quais não lhes foram formalmente apresentados em cursos de mestrado ou doutorado, por eventos acadêmico-profissionais da área ou por ações formativas em suas próprias instituições.

Ainda no que se refere às observações de aula, ressalta-se que o fato de não haver um protocolo de observação já existente na literatura da área, pelo menos até onde se sabe, desenhado especificamente para a sala de aula de ensino de prática da Tradução, limitou o rol de categorias ao conhecimento da pesquisadora e às obras consultadas (COHEN et al., 2018). Serão necessárias outras pesquisas relacionadas a protocolos de observação de aulas, talvez em áreas correlatadas à Tradução, que possam tentar aperfeiçoar a aferição de outras formas de interação entre professores e alunos, revelando assim as fortunas presentes nas aulas de tradução. Além disso, seria aconselhável implementar pesquisas dessa natureza utilizando dois ou mais observadores, munidos com o mesmo protocolo, com vistas a apresentar maior confiabilidade dos dados e aprimoramento do instrumento, principalmente para não haver anotação da interpretação do pesquisador e sim do fenômeno.

Seria igualmente aconselhável que o papel do pesquisador, embora prezando a não intrusão, pudesse ser de caráter participante. O pesquisador participante pode colaborar com os sujeitos do contexto investigado e vice-versa, fazendo com que seus resultados surtam efeito formativo imediato, e despertando neles os princípios da etnografia crítica, em que o professor, 
em parceria com o pesquisador, reflete sobre suas abordagens pedagógicas. Nesse sentido, o trabalho de Darin (1997) é exemplar e inspirador.

Ao contribuir com a elaboração de um protocolo de observação, e futuramente munido desse instrumento, o professor de Tradução pode se perguntar por que utiliza, por quanto tempo, e quais os efeitos de uma determinada abordagem para a aprendizagem dos seus alunos, e, mais importante, quais as possíveis formas de se desprender do "complexo de Atlas", já que as práticas da tradução se alteram a cada dia a partir dos novos artefatos tecnológicos e é impossível ao professor manejar por completo todas as suas especificidades.

A despeito de suas limitações, espera-se que os resultados da presente pesquisa possam contribuir para a gestão do conhecimento socialmente construído sobre como formar tradutores, almejando novas frentes de estudo que tenham como foco o professor de Tradução.

\section{REFERÊNCIAS}

ARROJO, R. Tradução, desconstrução e psicanálise. Rio de Janeiro: Imago Ed., 1993.

162 ARROJO, R. The revision of the traditional gap between theory \& practice and the empowerment of translation in postmodern times. The Translator, v. 4, n. 1, p. 25-48, 1998.

BIAZI, T. M.; GIMENEZ, T.; STUTZ, L. O papel da observação de aulas durante o Estágio Supervisionado de Inglês. SIGNUM, n. 14/1, p. 57-78, jun. 2011.

COLINA, S. Ensino de tradução: da pesquisa à sala de aula. Diretrizes para professores. Traduzido por: Marileide Dias Esqueda et al. Uberlândia: EDUFU, 2015.

CHARLOT, B. Da relação com o saber: elementos para uma teoria. Traduzido por: Bruno Magne. Porto Alegre: Artes Médicas Sul, 2000.

CHARLOT, B. (org.). Os jovens e o saber: perspectivas mundiais. Porto Alegre: Artes Médicas, 2001.

CHARLOT, B. (org.). Relação com o saber, formação dos professores e globalização: questões para a educação hoje. Porto Alegre: Artmed, 2005.

COHEN, L. et al. Research Methods in Education. New York: Routledge, 2018.

CORMIER, M. En torno a una pedagogía centrada en el estudiante: el método "Aprendizaje a través de problemas" aplicado a la terminología. Onomazein v. 3, p.177-193, 1998.

DARIN, L. C. de M. Pesquisa em sala de aula: a prática na tradução na prática. Tradterm 4, n. 2, p. 97-128, 1997. 
DARIN, L. C. de M. Exame crítico do ensino da tradução em nível universitário. Contexturas, n. 5, p. 59-78, 2001.

DELISLE, J. La traduction raisonnée: manuel d'initiation à la traduction professionnelle de l'anglais vers le français. Ottawa: Ottawa University Press, 2013.

ECHEVERRI, A. El alumno de traducción centro de la formación: conócete a tí mismo y... Belas Infiéis, 2015, v. 4, n.2, p. 9-35.

ECHEVERRI, A. El aprendizaje activo en la formación de traductores, declaración de principios. In: PEREIRA, G. H.; COSTA, P. R. (org.). Formação de tradutores: por uma pedagogia e didática da tradução no Brasil. Campinas, SP: Pontes Editores, 2018, p. 21-48.

ECHEVERRI, A. Énième plaidoyer pour l'innovation dans les cours pratiques de traduction. Préalables à l'innovation? TTR, Montréal, v. 21, n. 1, p. 65-98, 2008.

ESQUEDA, M. D. Ensino de Tradução: Culturas Pedagógicas. Trabalhos em Linguística Aplicada, Campinas, vol. 57, $\mathrm{n}^{\mathrm{o}}$ 2, p. 1244-1273, 2018. Disponível em: https://periodicos.sbu.unicamp.br/ojs/index.php/tla/article/view/8651880/18340. Acesso em: dez. 2019.

FIOLA, Marco. Prolégomènes à une didactique de la traduction professionnelle. META. Montréal, v. 48, n.3, p. 336-346, 2003a.

FIOLA, M. A. La notion de programme en didactique de la traduction professionnelle: le cas du Canada. 2003. 383 f. (Thèse de doctorat inédite) - École Supérieure d'Interprètes et de Traducteurs, Université Paris III - Sorbonne Nouvelle, Paris, 2003b.

FLORES, M. A. Investigar (com) os professores: reflexões sobre uma pesquisa longitudinal. Perspectiva, Florianópolis, v. 21, n. 2, p. 391-412, jan. 2003. DOI: https://doi.org/10.5007/\%x. Disponível em: https://periodicos.ufsc.br/index.php/perspectiva/article/view/9756/8990. Acesso em: dez 2019.

FEIMAN-NEMSER, S. From preparation to practice: Designing a continuum to strengthen and sustain teaching. Teachers College Record, v.103, n. 6, p. 1013-1055, 2001.

FREITAS, R. A. M. da M. Ensino por problemas: uma abordagem para o desenvolvimento do aluno. Educação e Pesquisa, v. 38, n. 2, p. 403-418, 2012. Disponível em: http://www.scielo.br/pdf/ep/2011nahead/aop478.pdf. Acesso em: dez 2019.

GAMBIER, Y. Teaching Translation and Training Translators. In: Gambier, Y.; DOORSLAER, L.V. (org.) Handbook of Translation Studies, 2012, v. 3, p. 163-171.

GIORGI, C. A. G. et al. Necessidades formativas de professores de redes municipais: contribuição para a formação de professores crítico/reflexivos. 1. ed. São Paulo: Cultura Acadêmica/Editora UNESP, 2010.

GILE, D. Basic concepts and models for interpreter and translator training. Amsterdam, Philadelphia: John Benjamins, 2009. 
GONZÁLEZ-DAVIES, M. Multiple voices in the translation classroom. Amsterdam: John Benjamins, 2004.

HUBERMAN, M. O ciclo de vida profissional dos professores. In: NÓVOA, A. (org.). Vidas de professores. 2 ed. Porto: LDA, 1995. p. 31-59.

KELLY, D. A handbook for translator trainers: a guide to reflective practice. Manchester, UK: St. Jerome, 2005.

KELLY, D. Translation Didactics. In: GAMBIER, Y.; VAN DOORSLAER, L. (org.). Handbook of translation studies. Amsterdam/Philadelphia: John Benjamins Publishing, vol. $1,2010$.

KIRALY, D. From assumptions about knowing and learning to praxis in translator education. InTRAlínea, v. 16, p. 1-11, 2014.

KIRALY, D. A social constructivist approach to translator education: empowerment from theory to practice. Manchester: St. Jerome, 2000.

KIRALY, D. Pathways to translation: Pedagogy and process. Kent, Ohio: Kent State University Press, 1995.

164 LADMIRAL, J-R. Traduire: Théorèmes pour la traduction. Paris: Petite Bibliothèque Payot. 1979.

NODARI, J. I; ALMEIDA, M. R. Refletindo sobre a agência docente através da observação de aulas. Revista X, v. 2, p. 24-46, 2012.

NORD, C. Training functional translators. Cadernos de tradução, v. 1, n. 5, p. 27-46, 2000.

PIMENTA, S. G. Saberes Pedagógicos e atividade docente. 8. ed. São Paulo: Cortez Editora, 2016.

SELESKOVITCH, D.; LEDERER, M. La pédagogie raisonnée de l'interprétation. Coll. Traductologie 2. Paris, France: Dédier, 1989.

TARDIF, M. Saberes docentes e formação profissional. 3. ed. Petrópolis: Vozes, 2002.

VENUTI, L. (org.) Translation Teaching: programs, courses, pedagogies. New York, NY: Routledge, 2017.

VINAY, J.-P.; DARBELNET, J. Stylistique comparée du français et de l'anglais: méthode de traduction. Paris, France: Dédier, 1958.

VYGOTSKY, L. S. A formação social da mente. Traduzido por: José Cipolla Neto et al. São Paulo: Martins Fontes, 1998.

WALFORD, G. Doing Qualitative Educational Research: A Personal Guide to the Research Process. London: Continuum, 2001. 


\begin{abstract}
* Marileide Dias ESQUEDA - Doutora (2005) e Mestre (1999) em Linguística Aplicada pela Universidade Estadual de Campinas. Bacharel em Tradução (1995) pela Universidade Sagrado Coração. Realizou estágio de pós-doutorado na Université de Montréal, Canadá. Professora associada da Universidade Federal de Uberlândia. Uberlândia, Minas Gerais, Brasil.
\end{abstract}

Currículo acadêmico: http://lattes.cnpq.br/3341029625579574

ORCID: https://orcid.org/0000-0002-6941-7926

E-mail: marileide_esqueda@hotmail.com

${ }^{1}$ ESQUEDA (2018) utiliza, em português, "conferência magistral" para se referir à performance magistrale. O termo "conferência", para a autora, estaria atrelado a dois sentidos: "conferência", como ato de conferir, corrigir, dar a palavra final, neste caso pelo professor, e também ao discurso prolongado do professor em sala de aula, que raramente prevê a participação dos alunos, sendo que tal fórmula, geralmente utilizada em disciplinas teóricas, também se faz presente nas aulas de prática da tradução.

${ }^{2}$ En el caso de la performance magistrale, el trabajo de los alumnos cuenta poco porque lo que en última instancia habrá que retener son las soluciones de traducción propuestas por el profesor. Es en ese sentido que la idea de igualar el desempeño profesional del profesor no puede ser el objetivo final de la formación. Visto de esta manera, la presencia de los alumnos en los cursos de traducción no determina ni la calidad ni la cantidad de lo aprendido. Ante esta situación, la pregunta que surge naturalmente es: ¿Cómo explicar que la práctica de la performance magistrale se perpetúe?

${ }^{3}[. .$.$] while this instructional practice has been pervasive until recent years, little has been written about where$ this particular pedagogical technique comes from and why it seems to persist as a mainstay in the education of professional translators. No one seems to have invented it specifically for use in translation practice classes or, at least, there do not seem to be any translation didactic scholars who proudly claim responsibility for having created it. So there is some evidence that the 'Who will take the first sentence?' approach is perhaps indeed based on a folk epistemology and a hand-me-down praxis perpetuated by tradition - and a perceived lack of viable alternatives.

${ }^{4}$ Cf.: https://arts.uottawa.ca/translation/summer-programs/ttpp

http://traduzione-editoria.fusp.it/summer-school-eslt-2019_5.html

${ }^{5}$ Registro número 00676013.1.0000.5152 na Plataforma Brasil/Comitê de Ética e Pesquisa.

${ }^{6}$ Não fez parte do escopo deste estudo restringir a coleta de dados junto a professores de uma determinada prática de tradução (literária, técnico-científica, jurídico-comercial ou outra). Nesta e nas demais etapas da pesquisa, contou-se com os dados dos professores que aceitaram participar do estudo.

${ }^{7}$ Selecionou-se uma universidade canadense para a realização da terceira etapa da pesquisa por dois motivos: em primeiro lugar, porque o Canadá, por ser um país bilíngue, possui forte tradição na formação de tradutores desde a década de 1940, tornando-se uma fonte rica para o estudo do ensino da Tradução (FIOLA, 2003b). Em segundo lugar, porque esse foi o país escolhido pela autora deste artigo para a realização de seu estágio pós-doutoral entre os anos de 2018 e 2019, facilitando o acesso ao contexto de ensino da Tradução.

${ }^{8}$ El reto inmediato de la pedagogía de la traducción es superar esa última frontera que es el aula de clase.

${ }^{9}$ As observações de aulas dos participantes envolvidos foram implementadas durante a realização do estágio pósdoutoral da autora desta pesquisa, entre os anos de 2018 e 2019.

${ }^{10}[\ldots]$ interviewers and interviewees co-construct the interview.

${ }^{11}$ Por questões de espaço, não serão detalhadas as exigências de contratação de docente mestres e doutores dos contextos investigados.

${ }^{12}$ On the whole, selecting texts for translation classes is not a matter of adhering to rigid principles - nor is it a matter of mere intuition. It is a fundamental requirement in translation teaching that only authentic texts should be used as material, i.e. real texts-in-situation, and that they should be practice-relevant. This means that in a culture like Germany, where newspaper articles are hardly ever translated because the big newspapers have their own correspondents all over the world, newspaper texts play a secondary role in translation classes, if any - they may be quite useful when dealing with translation problems like culture-bound realities (realia) or citations. All source texts have to be presented to the students in such a way that as much information as possible is provided on the situation in which the original is or was used in order to make the task more realistic.

${ }^{13}$ Por questões de espaço, não são relatados os impactos dessa abordagem nos contextos de ensino de outras áreas.

${ }^{14}$ Embora transcorridos cerca de 21 anos entre a pesquisa de CORMIER (1998) e a data da coleta de dados da presente pesquisa, realizada em 2019, até onde se tem conhecimento, não foram encontrados relatos empíricos ou descritivos, nos Estudos da Tradução, que comparem a adoção dessa abordagem a outras.

ESQUEDA, Marileide. Ensino de tradução: Perfis e abordagens pedagógicas de docentes brasileiros e canadenses. Belas Infiéis, Brasília, v. 9, n. 1, p. 127-166, 2020. 
15 [...] utilizing group dynamics does not always help all the students in the same way and to the same degrees. Some questions remain. When to introduce teamwork in the learning process? How to make sure that all the students are motivated and active and are working together and not against each other?

${ }^{16}$ Ningún otro manual ha tenido ni el impacto ni la influencia que el manual de Delisle ha tenido en la formación de traductores canadienses en los ya casi cuarenta años desde la publicación de su primera versión. Este es un buen indicio de lo poco que ha cambiado la educación de traductores en Canadá. 